\title{
Measurements of F'ossible Type Inversion in Silicon Junction Detectors by Fast Neutron Irradiation*
}

\author{
Z. Li and H. W. Kraner \\ Brookhaven National Laboratory, Upton, NY
}

\section{INTRODUCTION}

The successful application of silicon position sensitive detectors in experiments at the SSC or LHC depends on an accurate assessment of the radiation tolerance of this detector species. In particular, fast neutrons $\left(E_{a v}=1 \mathrm{MeV}\right)$ produce bulk displacement damage that is projected, from estimated fluences, to cause increased generation (leakage) current, charge collection deficiencies, resistivity changes and possibly semiconductor type change or inversion. Whereas the leakage current increase was believed to be the major concern for estimated fluences of $10^{12}$ $\mathrm{n} / \mathrm{cm}^{2}$ experiment year at the initial SSC luminosity of $10^{33} / \mathrm{cm}^{2}-\mathrm{sec}$, increased luminosity and exposure time has raised the possible exposure to $10^{14} \mathrm{n} / \mathrm{cm}^{2}$, which opens the door for the several other radiation effects suggested above to play observable and significant roles in detector degradation or change.

*This research was supported in part by the U. S. Department of Energy: Contract No. DE-AC02-76CH00016. 
The increase in leakage current of a detector having active volume, $V$, is characterized by a rate constant, the damage coefficient, $\alpha$, that has been well-studied $[1,2,3]$ and is given by consensus as

$$
\begin{gathered}
I_{L}=\alpha V \phi \\
\alpha=8 \times 10^{-17} \mathrm{~A} \mathrm{~cm}^{-1} \text { for } 1 \mathrm{MeV} \text { neutrons. }
\end{gathered}
$$

The generation centers induced in the material must be near the middle of the band gap to be effective; the $E$ center, the vacancy-phosphorus complex at $E_{C}-0.45 \mathrm{eV}$ or the deviancy at $\sim E_{C}-0.39 \mathrm{eV}$ are candidates for this effect $[1,4,5,6]$. Studies of the levels induced in high resistivity material — n type - continue by deep level transient spectroscopy $[1,4]$.

Majority carrier removal characterizes the increase in apparent material resistivity [1] through either compensation of shallow donors (or acceptors) by deep traps or the removal of substitutional donors (or acceptors) by formation of vacancy-donor (acceptor) complexes. Early accepted values for removal rates [7] of have been augmented by recent values [1] which are in substantial agreement. As indicated in [2] significant alteration of material may occur in the $10^{13} \mathrm{n} / \mathrm{cm}^{2}$ range of fluence.

Unfortunately the simple and standard method for determining material bulk resistivity, the capacitance of the junction as a function of voltage and determination of full depletion voltage, is impaired by the introduction of deep level damage [8] and the exact nature of material resistivity is difficult to ascribe after moderate fast neutron dose. This picture is further complicated by the fact that in nominal $4 \mathrm{k} \Omega \mathrm{n}$-type detector grade material having $N_{D}(P h)-$ $10^{12} / \mathrm{cm}^{3}$, (and $\left.N_{A}(B) \sim .3 \times 10^{12} / \mathrm{cm}^{3}[10]\right), E_{F}$ is about $\simeq E_{C}-0.3 \mathrm{eV}$. Introduction of relatively few (e.g., $5 \times 10^{12} / \mathrm{cm}^{3}$ ) "deep" levels will surely position $E_{F}$ among the inducei 
levels, compensating $N_{D}$, and creating a very complicated picture of the material as a semiconductor with concomitant difficulty of defining a material type. The behavior of material bulk resistivity with radiation dose is often portrayed schematically and a comprehensive study has made by Lugakov, et al. [9] using Hall measurements to determine carrier concentrations. Fretwurst, Lindstroem, et al. [2] have used the method of applying an $\alpha$ source to both sides of a $\mathrm{p}^{+} \mathrm{n} \mathrm{n}^{\pi}$ structure as a function of fluence to measure a shift in the operative junction from $\mathrm{p}^{+} \mathrm{n}$ to $\mathrm{pn}^{+}$thereby measuring a type inversion. This method is a variant of a method used some time ago to determine which carrier type undergoes most trapping or charge collection degradation [10]. Efforts to date to reproduce these measurements have raised more questions than answers, the status of which form the bulk of this report.

It is recognized that the devices used in this study differ somewhat in technology from those produced by Lindstroem which are surface barrier detectors with thermal oxide edge protection on n-type material with an ohmic (?) Al back contact. These wafers have undergone a thermal oxidation of edges growing $2700 \mathrm{~A}$ in dry oxygen at $975-1050^{\circ} \mathrm{C}$. The devices used here are "standard" planar technology-produced detectors of 0.25 or $1 \mathrm{~cm}^{2}$ having B-implanted $\mathrm{p}^{+}$and As-implanted $\mathrm{n}^{+}$contacts. In addition to a three temperature oxidation cycle [11]-in most cases - they have endured an additional $1 \mathrm{hr} 700^{\circ} \mathrm{C}$ post implantation anneal in $N_{2}$ and a short $450^{\circ} \mathrm{C} \mathrm{Al} \mathrm{metallization} \mathrm{sintering.}$

Irradiation with fast neutrons produced by the ${ }^{7} \mathrm{Li}(p, n){ }^{7} \mathrm{Be}^{*}$ reaction was carried out at the University of Lowell van de Graaff acceletiator as in previous studies [12]. 


\section{RESULTS}

To illustrate the difficulty in deriving depletion depth from $\mathrm{C}(\mathrm{V})$ measurements, Fig. 1 shows the $\mathrm{C}(\mathrm{V})$ measurements at several bridge frequencies [8] for a detector irradiated at very low fluence, $7 \times 10^{10} \mathrm{n} / \mathrm{cm}^{2}$, and further irradiated to $7.8 \times 10^{12} \mathrm{n} / \mathrm{cm}^{2}$. The increase of resistivity from $6 \mathrm{k} \Omega-\mathrm{cm}$ to $16 \mathrm{k} \Omega-\mathrm{cm}$ can be discerned from the change in full depletion voltage from $60 \mathrm{~V}$ to $20 \mathrm{~V}$ as measured by the low frequency $\mathrm{C}(\mathrm{V})$ measurement. At higher doses, the depletion voltage is more difficult to measure with some precision even at very low bridge frequencies.

In addition to comparing the $\alpha$ particle response for front and back incidence, two othe: methods and structures have been employed: (1) the observation of type of accumulated charge under a MOS capacitor and (2) the I(V) characteristic of $\mathrm{p}^{+} \mathrm{np}{ }^{+}$or $\mathrm{p}^{+} \mathrm{pp}^{+}$structures in detectors themselves or configurations on detector grade material. Specifically, MOS capacitors on a test wafer are used for each oxidation run to determine oxide quality and wafer surface quality; a large inventory of up to $3 \mathrm{~mm}$ diameter MOS capacitors is available. Further, most test diodes of 0.25 or $1 \mathrm{~cm}^{2}$ are produced with a guard "ring" or band peripheral to the front implanted contact which is implanted with the same ion as the large area contact. A simple $\mathrm{p}^{+} \mathrm{np}^{+}$ structure (or $\mathrm{n}^{+} \mathrm{pn}^{+}$) thereby directly available.

\section{A. MOS Capacitors}

Figure 2 shows the expected capacitance-voitage $(C(V))$ response of MOS capacitors on both $\mathrm{n}$ and p-type material, the change from accumulation to depletion requiring either 
significant positive or negative bias depending on majority carrier. The shift of "flat band voltage" to a slightly negative value is due to the predominantly positive fixed charges in the oxide and interface.

Figure 3 shows the $C(V)$ response of the capacitor on n-type material (from Figure 2 N5C) after fluences to $3.7 \times 10^{13} \mathrm{n} / \mathrm{cm}^{2}$ as measured at $10 \mathrm{kHz}$ bridge frequency. The majority carrier accumulated under the $\mathrm{Si}-\mathrm{SiO}_{2}$ interface is clearly still electrons. It should be noted that first-order C(V) effects [8] do not depend on crossings of the Fermi level with un-ionized deep levels in this method. However, these measurements were made at $10 \mathrm{kHz}$ which does lend itself to "quasi static" effects in the fully depleted mode at larger negative biases. A similar result is shown in Figure 4 which contrasts $5 \mathrm{k} \Omega$ material with the $2 \mathrm{k} \Omega$ material of Figure 3; again the majority carrier continues to be electrons although an enhanced minority carrier effect is evident. Figure 5 shows a MOS structure that was irradiated in two steps: first to $1.37 \times$ $10^{13} \mathrm{n} / \mathrm{cm} 2$ and following 50 days at room temperature an additional irradiation to $4.37 \times 10^{13}$ $\mathrm{n} / \mathrm{cm} 2$. The anneal did change the minority carrier effect, but further irradiation did not produce any indication of type change.

\section{B. Guard Ring-Diode Structures}

As a control for this study the $\mathrm{p}^{+}$front contact structure was made on $\mathrm{p}$-type material to demonstrate the simple resistive $\mathrm{p}^{+} \mathrm{pp}^{+} \mathrm{I}(\mathrm{V})$ characteristic, shown in Figure 6(a). Figure 6(b) shows the I(V) response of the same structure on n-type material which is clearly that of back-toback diodes, $\mathrm{p}^{+} \mathrm{np}^{+}$, as expected. The devices were not depleted by bias from the back $\mathrm{n}+$ contact. Figure 7 shows the I(V) response of the same configuration and wafer as Figure $6(\mathrm{~b})$ 
following $1.37 \times 10^{13} \mathrm{n} / \mathrm{cm}^{2}$ in which it is clear that an $\mathrm{n}$-type base material persists. Another identical device, wafer 1001, is shown in Figure 8 after $5.5 \times 10^{13} \mathrm{n} / \mathrm{cm}^{2}$ (with considerably more leakage current) and it still appears to be a $\mathrm{p}^{+} \mathrm{np}^{+}$structure. The fact that the back-toback $I(V)$ characteristics match almost perfectly with the reverse $I(V)$ characteristics of their corresponding diodes also shows that the rectifying junctions are still on the front (i.e., $p^{+} / n$ ) of the detector.

\section{Front and Back Side Alpha Particle Illumination}

Irradiated detectors were mounted on G10 printed circuit boards having a hole in the back contact to permit access of the $\alpha$-particles to the thin back contact. The back contact was connected to outside electronics with silver conductive epoxy and the front contact by wire bonding to copper pads. Both front and back contacts are implanted and should be essentially "thin" for the spectroscopy employed here. Conventional nuclear physics electronics consisting of an Ortec 142B preamplifier and 572 spectroscopy amplifier and multichannel analyzer (MCA) were used to observe the alpha signals. Bias could be applied to the back of the detector or the front given the ac coupled preamplifier. For the results reported, the back contact was grounded, the preamplifier attached to the front $\left(\mathrm{p}^{+}\right)$contact of device was ac coupled and the $\mathrm{p}^{+}$guard ring was allowed to float, uncontacted. The preamplifier rise time was about $50 \mathrm{nsec}$ and shaping times of interest could be selected in the 0.5 to $2 \mu \mathrm{sec}$ range. A thin ${ }^{241} \mathrm{Am}$ or a more intense ${ }^{244} \mathrm{Cm}$ alpha source was used.

Initial observations of pulse height in the MCA as a function of bias of a detector damaged with $6 \times 10^{12} \mathrm{n} / \mathrm{cm}^{2}$ suggested too great a dependence of pulse height on bias and 
direct observation of the unshaped, undifferentiated pulse from the preamplifier with a digital storage oscilloscope showed generally slowly rising signals on the order of the shaping times - $\mu \mathrm{sec}$ - accounting for the apparent charge loss seen in the MCA. The pulse rise times were generaily strongly bias dependent. Pulse shapes for both front and back alpha incidence were found to be strongly bias dependent for detectors having more than $6 \times 10^{12} \mathrm{n} / \mathrm{cm}^{2}$ fluences.

Before going into details of irradiated detectors, it is instructive to consider a control or unirradiated detector; preamplifier output pulses for which are shown in Figure 9. For all the data shown in this section, a clean fast-rising pulse of $160 \mathrm{mV}$ as given by the front irradiation at only $20 \mathrm{~V}$ bias results in a good resolution single peak of essentially full charge collection. This $4 \mathrm{k} \Omega$ material depletes the $310 \mu \mathrm{m}$ wafer thickness at $50 \mathrm{~V}$ and a clear full signal is realized at that bias for alpha incident on the back contact. At $20 \mathrm{~V}$ bias the detector is depleted $150 \mu \mathrm{m}$ and nearly full charge is collected by diffusion of the alpha ionization from the region of the back contact within about $15 \mu \mathrm{sec}$, which sets a diffusion time scale for $150 \mu \mathrm{m}$.

Figures 10 and 11 show two detectors, $133-9$ and 130-10, irradiated with $6 \times 10^{12}$ $\mathrm{n} / \mathrm{cm}^{2}$. Several other results with detectors from wafer 133 will be presented for direct comparisons, however, the results from a slightly dissimilar material grown with a "standard" "C" oxide [11] should be given also. At this fluence, both devices do not achieve full charge collection for alpha incident on the front until a bias of at least 150 volts is used. In this $\mathrm{p}^{+} \mathrm{n}$ structure, the field originates from the front contact and should be present at low biases; electrons are making the full transit of the detector in this geometry. Both the rise time and charge collected is degraded, however, at low biases, suggesting some carrier (electron) trapping 
especially at low carrier velocities which may pertain if the field distribution is altered towards lower fields through a significant portion of the device.

When alpha are directed to the back of the detector, no pulses are visible at the preamplifier output until $150 \mathrm{~V}$ is applied, after which (for both devices shown) full collection is achieved only with $300 \mathrm{~V}$. At $150 \mathrm{~V}$, the pulse rise time is very slow, perhaps $40 \mu \mathrm{sec}$, and only about $1 / 3$ of the charge is collected. However, with 250 or $300 \mathrm{~V}$ applied, very nearly full charge can be collected within amplifier shaping times.

Figure 12 shows the experimental result from detector 107-1 which received only $5 \times$ $10^{11} \mathrm{n} / \mathrm{cm}^{2}$. No apparent effect was noticed for alpha incident on the front contact, however no alpha were visible for incidence on the back contact until $50 \mathrm{~V}$ was applied. This is contrasted to the undamaged detector, Figure 9, which showed considerable collection by diffusion from the back at only $20 \mathrm{~V}$ bias. Trapping of the more slowly moving charge (holes) during diffusion is therefore considerable. As in the cases at $6 \times 10^{12} \mathrm{n} / \mathrm{cm}^{2}$, full collection within shaping times can be achieved with additional bias, in this case only $100 \mathrm{~V}$.

Detector $133-2$ received $1.6 \times 10^{13} \mathrm{n} / \mathrm{cm}^{2}$ and the preamplifier pulses are shown in Figure 13. At lower biases, $<100 \mathrm{~V}$, alpha could not be seen for incidence on either contact, however at $200 \mathrm{~V}$, the alpha signal is clearly larger for incidence on the front contact. At 300 $\mathrm{V}$, the front contact incidence signal shows almost two components, about half the signal being fast followed by a much slower portion; the back contact pulses do not appear to have this division into fast and slow. Again, nearly full collection for incidence from either contact can be achieved if large biases are applied, somewhat less is required for the front contact incidence. 
Detector 1001-27 received $5 \times 10^{13} \mathrm{n} / \mathrm{cm} 2$ and its response is shown in Figure 14. Alpha were not really visible for front contact incidence until $300 \mathrm{~V}$ was applied; they are seen at 200 $\mathrm{V}$ for back contact incidence. In both geometries considerable trapping degrades charge collection. Apparently a higher field is present near the front contact as pulses at all biases have somewhat shorter rise time, in some manner similar to the short component ascribed to the front contact incidence for detector $133-2$ at $1.6 \times 10^{\mathrm{i} 3} \mathrm{n} / \mathrm{cm}^{2}$.

\section{Modelling}

Deep acceptor-like defect levels have been modeled to rearrange the linear field in junction devices $[13,14,15]$. In order to explain the effect that the full depletion voltage measured by low frequency $\mathrm{C}(\mathrm{V})$ technique increases with neutron fluence at high fluences, as it is shown in Figure 15, and the effect of slow $\alpha$ source responses for detectors damaged to $\phi_{n}$ $\geq 6 \times 10^{12} \mathrm{n} / \mathrm{cm}^{2}$, a model using a donor-like defect level close to the Fermi level which becomes dominant at high neutron fluence is proposed here. Figure 16 shows the energy band diagram of the model, where for simplicity and clarity other levels (acceptor-like) proposed previously [8] are omitted without affecting the generality of the arguments here.

The electrical field $E(x)$ (E-field) is the solution of the Poisson equation:

$$
\epsilon \epsilon_{0} \frac{d^{2} \phi}{d x^{2}}=\rho(x)=\left\{\begin{array}{cr}
0 & x \leq-W_{p} \\
-e N_{A} & -W_{p}<x \leq 0 \\
e\left(N_{d}+N_{t d}\right) & 0<x \leq x_{t d} \\
e N_{d} & x_{z d}<x \leq W_{n} \\
0 & x>W_{n}
\end{array}\right.
$$


which is the following:

$$
E(x)=\left\{\begin{array}{cr}
0 & x \leq-W_{p} \\
-\frac{e N_{A}}{\epsilon \epsilon_{0}}\left(x+W_{p}\right) & -W_{p}<x \leq 0 \\
\frac{e\left(N_{d}+N_{t d}\right)}{\epsilon \epsilon_{0}} x-\frac{e N_{A}}{\epsilon \epsilon_{0}} W_{p} & 0<x \leq x_{t d} \\
\frac{e N_{d}}{\epsilon \epsilon_{0}}\left(x-W_{n}\right) & x_{t d}<x \leq W_{n} \\
0 & x>W_{n}
\end{array}\right.
$$

Where $N_{t d}$ is the concentration of donor-like defect levels and

$$
\left\{\begin{array}{l}
W_{n}=\frac{N_{t d}}{N_{d}+N_{t d}} \sqrt{\frac{2 \epsilon \epsilon_{0} \phi_{t d}}{e N_{d}}}+\sqrt{\frac{2 \epsilon \epsilon_{0}}{e\left(N_{d}+N_{t d}\right)}\left(V_{D}-V-\phi_{t d} \frac{N_{t d}}{N_{d}+N_{t d}}\right)} \\
x_{t d}=W_{n}-\sqrt{\frac{2 \epsilon \epsilon_{0} \phi_{t d}}{e N_{d}}}
\end{array}\right.
$$

Figure 17 shows the calculated profile of the E-field in the detector with defect concentration $N_{t d}$ as a parameter. The calculation parameters are given in the figure. It is clear that as $N_{\imath d}$ increases (when $\phi_{n}$ increases), the E-field is increasingly confined to the $\mathrm{p}^{+} / \mathrm{n}$ junction, leaving little or no E-field in the vast bulk of the detector. The full depletion voltage over $300 \mu \mathrm{m}$ silicon $\left(V_{d e p}\right)$ as a function of $N_{t d}$ calculated with the same set of parameters listed in Figure 17 are shown in Figure 18. The model predicts that $V_{d e p l}$ increases as $N_{d d}$ goes up, which agrees qualitatively with the data shown in Figure 15 and the observed effect that high voltage ( $V \geq 250$ volts) is needed to quickly collect ( $\sim 100 \mathrm{~ns}$ ) charges created by the $\alpha$-source situated on the back of a heavily damaged detector $\left(\phi_{n} \geq 6 \times 10^{12} \mathrm{n} / \mathrm{cm}^{2}\right)$. 
However, this model alone does not seem to explain why high voltage ( $V \geq 150$ volts) is also needed to quickly collect (within $100 \mathrm{ns)}$ ) charges created by the $\alpha$-source sitting on the front of a heavily damaged detector $\left(\phi_{n} \geq 6 \times 10^{12} \mathrm{n} / \mathrm{cm}^{2}\right)$. Since even with little or no field in the region of $5 \mu \mathrm{m} \leq x \leq 20 \mu \mathrm{m}$ ( $\alpha$-source range $R_{p}$ ), the diffusion alone would only take $340 \mathrm{~ns}$ for holes to be collected, and the observed $\alpha$-pulse rise time at $V=0$ volt is $t_{r} \geq 8 \mu \mathrm{sec}$ for $\phi_{n} \geq 6 \times 10^{12} \mathrm{n} / \mathrm{cm}^{2}$, it is clear that even a model of no-field and all diffusion does not explain the long rise time.

The rise time, $t_{r}$ can be written as:

$$
t_{r}= \begin{cases}\int_{R_{a}}^{0} \frac{d x}{\mu_{h} E(x)} & R_{\alpha} \leq W_{n} \\ \text { (Drifting) } & R_{\alpha}>W_{n} \\ \int_{W_{n}}^{0} \frac{d x}{\mu_{h} E(x)}+\frac{e\left(R_{\alpha}-W_{n}\right)}{K T \mu_{h}} & \\ \text { (Diffusion plus drifting) } & \end{cases}
$$

or

$$
t_{r} \propto \frac{1}{\mu_{h}}
$$

As it is suggested in Figure 19, if the hole mobility, $\mu_{h}$, is significantly degraded via shallow level trapping-detrapping process, the rise time, $t_{r}$, can be greatly affected. The possibility of the degradation of carrier mobilities due to heavy neutron damage is at this point only a speculation and specific experiments are needed to evaluate the model. 
In addition to the carrier trapping process that may affect carrier effective mobility, the carrier generation lifetime, $\tau_{g}$, recombination lifetime, $\tau_{r}$, which are related through the Eq. [16]:

$$
\begin{gathered}
\tau_{f}=2 \tau_{r} \sqrt{\frac{\sigma_{n}}{\sigma_{p}}} \cosh \left[\frac{\left(E_{t}-E_{i}\right)}{k T}\right] \\
-2 \tau_{r} \sim 50 \tau_{r} \text { (If } E_{t}-E_{l} \geq 4 k T \text { ) }
\end{gathered}
$$

also degrade significantly due to neutron induced deep levels. A characteristic length for a free carrier to diffuse before recombination is defined as:

$$
L=\sqrt{D \tau_{r}}
$$

and from Eq. (7),

$$
L \leq \sqrt{0.5 \tau_{g} D}
$$

For a detector with n-type substrate before radiation, the typical value for minority carrier generation lifetime, $\tau_{\mathcal{g}}$, is a few milliseconds. This leads to a minority carrier diffusion length,

$$
\begin{aligned}
& L_{h}^{0}-\sqrt{11 \mathrm{~cm}^{2} / \mathrm{sec} \cdot 10^{-3} \mathrm{sec}}=1 \mathrm{~mm} \\
& \text { or } L_{h}^{0}>d_{S i}(-300 \mu \mathrm{m}-400 \mu \mathrm{m})
\end{aligned}
$$

Therefore the carrier recombination in an un-irradiated detector has a minimum role. 
For an irradiated detector, the minority carrier diffusion length, $L_{g}$, is related to the neutron fluence, $\phi_{n}$, through the equation:

$$
\Delta J=\frac{\Delta I}{V}=\frac{e n_{i}}{2 \tau_{g}}
$$

and Eqs. (1) and (9) as follows:

$$
L_{h}\left(\phi_{n}, D_{h}\right) \leq \sqrt{5 \times 10^{6}\left(\mathrm{sec} / \mathrm{cm}^{2}\right) \cdot \frac{D_{h}}{\phi_{n}}}
$$

Where $\alpha=8 \times 10^{-17} \mathrm{~A} / \mathrm{cm}$ was assumed.

Provided that $D_{h}$ stays the same, $11 \mathrm{~cm}^{2} / \mathrm{sec}$, during the radiation (This may not be true as we have argued before and a reduction of $D_{h}$ after n-radiation would make $L_{h}$ even smaller.), one can write a high limit of $L_{h}$ as a function of $\phi_{n}$ :

$$
L_{n}\left(\phi_{n}\right)<74 \mu \mathrm{m} \sqrt{\frac{10^{12} / \mathrm{cm}^{2}}{\phi_{n}}}
$$

For as little as $5 \times 10^{11} \mathrm{n} / \mathrm{cm}^{2}$ fluence, $L_{h}$ is already degraded to $L_{h}<105 \mu \mathrm{m}<d_{s i}$, and recombination will take place at low biases for collecting holes created by the alphas on the back. This recombination of holes is evident in the data shown in Figure 12. 


\section{DISCUSSION AND CONCLUSIONS}

It is impossible in a few sets of measurement to fully unravel all of the complicated and interacting effects caused by neutron damage to silicon detectors. Charge collection times are observed as preamplifier rise times and are dependent on carrier velocities and potential distributions within the detector. Below saturation, the carrier velocity is proportional to the field-mobility product. We can speculate with a model on the electric field distribution and assume the carrier mobility is constant for each carrier type. However, we suggest the definition of an effective mobility that includes the effect of shallow level trapping and detrapping may be necessary to explain some results. Further, a definitive "type change" with radiation damage may be difficult to describe because of more complicated semiconductor effects involving in part field distributions and carrier trapping. Whereas it is almost customary to expect hole trapping, particularly as associated with damage clusters from shori range primary recoils, considerable electron trapping is also observed which emphasizes the importance of isolated defects.

Specific conclusions are listed:

1. Determinations of the accumulated majority carrier using irradiated MOS structures have been made for representative n-type base material up to fluences of almost $5 \times 10^{13} \mathrm{n} / \mathrm{cm}^{2}$ and indicate that the majority carrier remains electrons. It could be argued that if a material type inversion--or a tendency towards material intrinsic--had taken place in the fluence range above, say, $5 \times 10^{12} \mathrm{n} / \mathrm{cm} 2$ [c.f. 9], then in observations of diode behavior or conductivity behavior, the material would still appear to be n-type because of the greater electron mobility compared with holes. It may be pointed out that this argument would not apply to the MOS structure which depends on the charge of the majority carrier, not its movement. 
2. The guard ring structure on $p+n$ detectors provides a $p+\eta p+$ back-to-back diode structure with a very definitive $I(V)$ characteristic. The back-to-back diode characteristic remains in devices irradiated up to $5 \times 10^{13} \mathrm{n} / \mathrm{cm}^{2}$, further confirming that basic n-type behavior persists to this value.

3. Front and back side $\alpha$-particle incidence opened up several questions concerning charge collection after fast neutron irradiations to $5 \times 10^{13} \mathrm{n} / \mathrm{cm} 2$. Both hole and electron trapping are evident from the charge loss observed over the period of preamplifier rise times, $<100$ $\mu \mathrm{sec}$. As the loss over this period is well beyond conventional shaping times, it is at least a "trapping" effect (re-emission may take place) if not to some extent a carrier removal. Comparing Figures 9 and 12, it is clear that trapping also removes the diffusion component from collected charge induced at the undepleted back contact. There is no back side charge collected in the detector irradiated at $5 \times 10^{11} \mathrm{n} / \mathrm{cm}^{2}$ until the field reaches the back contact at depletion, $50 \mathrm{~V}$. At low biases, after $6 \times 10^{12}$ and $1.6 \times 10^{13} \mathrm{n} / \mathrm{cm}^{2}$ more charge is collected from the front contact illumination than the back. $500 \mathrm{~V}$ being required (10 times the initial depletion potential) for good backside collection.

Observed pulse rise times are generally quite slow for intermediate irradiation values: $6 \times 10^{12} \mathrm{n} / \mathrm{cm}^{2}$ and above, suggesting a low value of the mobility-field product through much of the detector volume. It is less imaginative to suggest regions of low fields due to the effects of deep levels and a model has been proposed which considerably shifts the field towards the $p+$ contact (Figure 16). This model also explains an apparent increase in voltage required to "deplete," or extent the field to the back contact with irradiation fluence which produces an apparent lowering of resistivity (possibly related to the attribution of type reversal to lowered 
resistivity [17]). What is not explained is the increased bias required for substantial charge collection at the front contact (Figures 10,11,13 and 14). The field distributions predicted in Figure 15 , do show a possibility for considerable field over the front $20-30 \mu \mathrm{m}$ necessary to include the entire $\alpha$-range, therefore much of the front contact incidence pulse should be short. If the field is confined to perhaps only the first few microns and becomes very low for some remaining portion of the $\alpha$-range and ionization (c.f. Fig. 19), charge collection should still take place by diffusion within about 300 nsec. To be sure, a fast rising component is observed in the detectors irradiated at intermediated fluences, however a complete description may have to include an apparent carrier mobility modified by relatively short trapping and detrapping periods (Figure 19).

Another means of determining field distribution or charge collection through out the detector volume is to measure the detection efficiency for a radiation which deposits a specific energy discretely through out the detector volume. The $60 \mathrm{keV}$ gamma rays from ${ }^{241}$ Am satisfy this requirement and measurements are under way to compare irradiated detector efficiencies.

4. It is concluded that a basic type inversion has not been observed for detectors damaged by fast neutrons up to fluences of $5 \times 10^{13} \mathrm{n} / \mathrm{cm}^{2}$, however other effects such as slow charge collection, carrier trapping and altered internal field distribution have been observed. 


\section{ACKNOWLEDGEMENTS}

Heipful discussions with V. Radeka, G. Lindstroem and E. Heijne are gratefully

acknowledged. We are indebted to Professor G. H. R. Kegel and the staff of the University of Lowell accelerator for their support during the fast neutron irradiations.

\section{BIBLIOGRAPHY}

1. E. Fretwurst, et al., Nucl. Instrum. Methods A 288, 1, (1990).

2. G. Lindstroem, et al., Presented at the International Conference on Calorimetry in High Energy Physics, (World Scientific Publishing Company, Singapore), (in press).

3. H. W. Kraner, Z. Li and K. U. Posnecker, Nuci. Instrum. Methods A 279, 266, (1989).

4. E. Borchi, et al., Nucl. Instrum: Methods A 279, 277, (1989).

5. L. C. Kimerling, J. Appl. Phys. 45, 1839, (1974).

6. L. C. Kimerling, IEEE Trans. Nucl. Sci. NS-23, 1497, (1976).

7. H. J. Stein, J. Appl. Phys., 38, 201, (1967).

8. Z. Li. and H. W. Kraner, IEEE Trans. Nucl. Sci 38, 244, (1991).

9. P. F. Lugakov, et al., Phys. Stat. Sol. (A) 74, 445, (1982).

10. H. W. Kraner, et al., in "Semiconductor Nuclear Particle Detectors and Circuits," Nat. Acad. Sci. Publication 1593 (1969), and Nucl. Instrum. Methods, 62, 173, (1968).

11. Z. Li and H. W. Kraner, IEEE Trans. Nucl. Sci. 36, 290, (1989).

12. G. H. R. Kegel, Computer Phys. Comm. 36, 321, (1985).

13. S. M. Ryvkin, et al., IEEE Trans. Nucl. Sci. NS-15, 226, (1968). 
14. D. K. Wilson, IEEE Trans. Nucl. Sci. NS-15, 77, (1968).

15. L. C. Kimerling, J. Appl. Phys. 45, 1839, (1974).

16. D. K. Schroeder, "The Concept of Generation and Recombination Lifetimes in Semiconductors,' " IEEE Trans. Elec. Dev., ED-29 (8), 1336-1338, (1982).

17. H. J. Ziock, et al., IEEE Trans. Nucl. Sci. 38, 269, (1991). 


\section{FIGURE CAPTIONS}

Figure 1. Capacitance-voltage relationships for a fast neutron irradiated silicon detector as a function of bridge frequency. (a) Shows the result at very low fluence, $7 \times$ $10^{10} \mathrm{n} / \mathrm{cm}^{2}$ and (b) is the result at a higher fluence, $7.8 \times 10^{12} \mathrm{n} / \mathrm{cm}^{2}$.

Figure 2. Capacitance-voltage (C(V)) responses of un-irradiated MOS capacitors with n-type and p-type substrates.

Figure 3. $\quad \mathrm{C}(\mathrm{V})$ responses of a MOS capacitor with $2 \mathrm{k} \Omega-\mathrm{cm}$ n-type substrate irradiated up to $3.7 \times 10^{13} \mathrm{n} / \mathrm{cm}^{2}$.

Figure 4. $\quad C(V)$ responses of a MOS capacitor with $5 \mathrm{k} \Omega$-cm n-type substrate irradiated up to $3.45 \times 10^{13} \mathrm{n} / \mathrm{cm}^{2}$.

Figure 5. $\quad C(V)$ responses of a MOS capacitor with $4 \mathrm{k} \Omega$-cm n-type substrate irradiated to $1.37 \times 10^{13} \mathrm{n} / \mathrm{cm}^{2}$ and, after 50 days $\mathrm{RT}$ anneal, irradiated again up to $4.37 \times$ $10^{13} \mathrm{n} / \mathrm{cm}^{2}$.

Figure 6. I(V) characteristics of (1) back-to-back diode $\left(\mathrm{p}^{+} / \mathrm{n} / \mathrm{p}^{+}\right)$; and (b) resistor $\left(\mathrm{p}^{+} / \mathrm{p} / \mathrm{p}^{+}\right)$before neutron radiation.

Figure 7. Back-to-back diode I(V) characteristics of detector 1001-2 and its guard ring after being irradiated to $1.37 \times 10^{13} \mathrm{n} / \mathrm{cm}^{2}$. The front-to-back I(V) characteristics of each diode are also shown.

Figure 8. Back-to-back diode I(V) characteristics of detector 1001-27 and 1001-28 after being irradiated to $5.5 \times 10^{13} \mathrm{n} / \mathrm{cm}^{2}$. The front-to-back $\mathrm{I}(\mathrm{V})$ characteristics of each diode are also shown. 
Figure 9. Preamplifier output pulses of an un-irradiated detector responding to alphas on the front and back.

Figure 10. Preamplifier output pulses of a detector irradiated to $6 \times 10^{12} \mathrm{n} / \mathrm{cm}^{2}$ responding to alphas on the front and back.

Figure 11. Preamplifier output pulses of a detector with different oxidation process irradiated to $6 \times 10^{12} \mathrm{n} / \mathrm{cm}^{2}$ responding to alphas on the front and back.

Figure 12. Preamplifier outpu: pulses of a detector irradiated to $5 \times 10^{11} \mathrm{n} / \mathrm{cm}^{2}$ responding to alphas on the front and back.

Figure 13. Preamplifier output pulses of a detector irradiated to $1.6 \times 10^{13} \mathrm{n} / \mathrm{cm}^{2}$ responding to alphas on the front and back.

Figure 14. Preamplifier output pulses of a detector irradiated to $5 \times 10^{13} \mathrm{n} / \mathrm{cm}^{2}$ responding to alphas on the front and back.

Figure 15. Full depletion voltage $\left(V_{\text {dep }}\right)$ from low frequency $\mathrm{C}(\mathrm{V})$ measurement as a function of neutron fluence.

Figure 16. Energy band diagram of the proposed model with a donor-like type defect level that becomes dominant at high neutron fluences and alters the electrical field in the detector.

Figure 17. Calculated electrical field profile in the detector as function of the concentration of the donor-like type defect level $\left(N_{r d}\right)$.

Figure 18. Calculated full depletion voltage $\left(V_{\text {dep }}\right)$ as a function of the concentration of the donor-like type defect level. 
Figure 19. Schematic of the degradarion of carrier mobilities via trapping-detrapping process through shallow defect level(s) introduced by neutron radiation. 


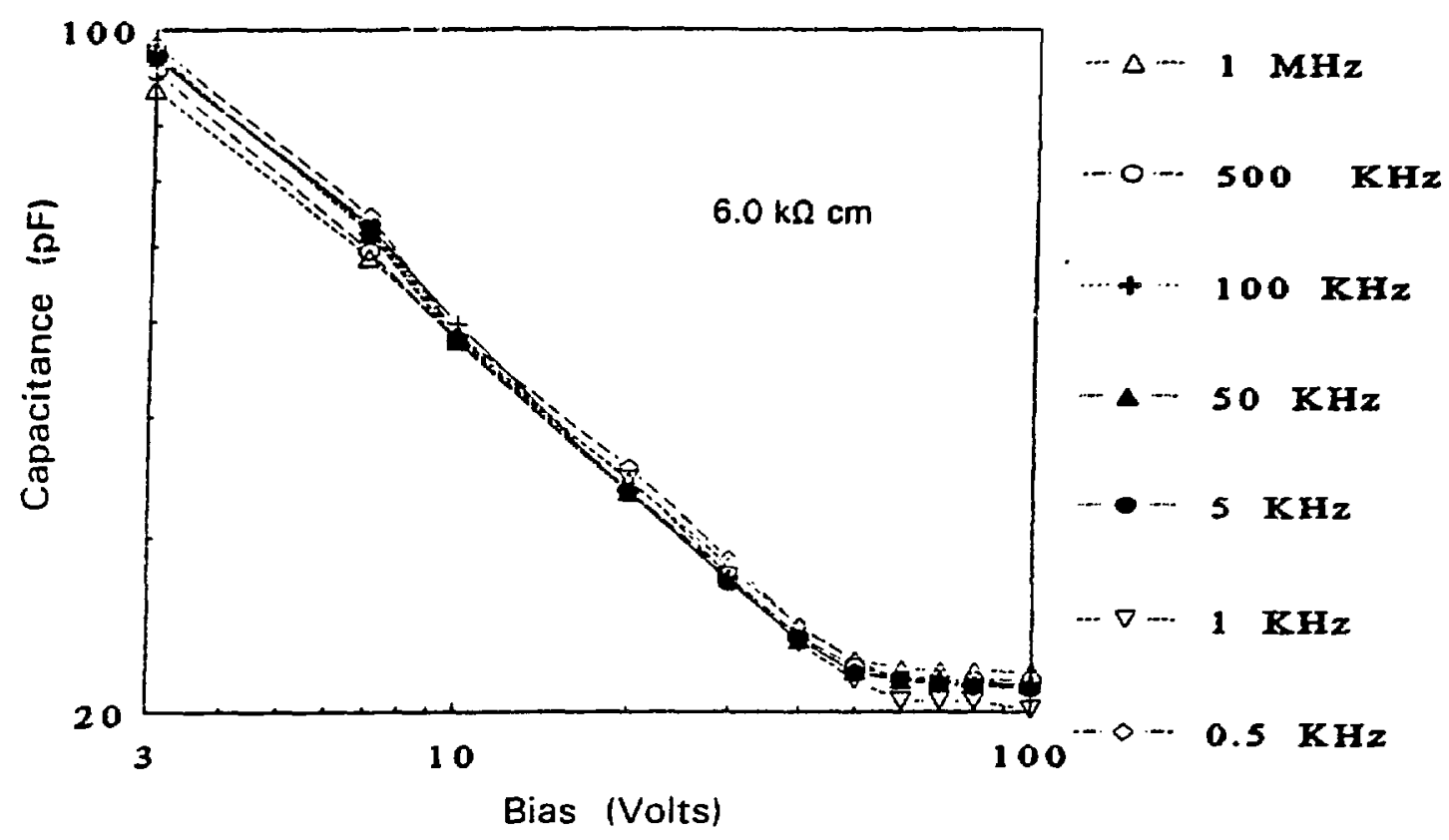

a) Neutron irradiated to the fluence of $7.0 \times 10^{10} / \mathrm{cm}^{2}$

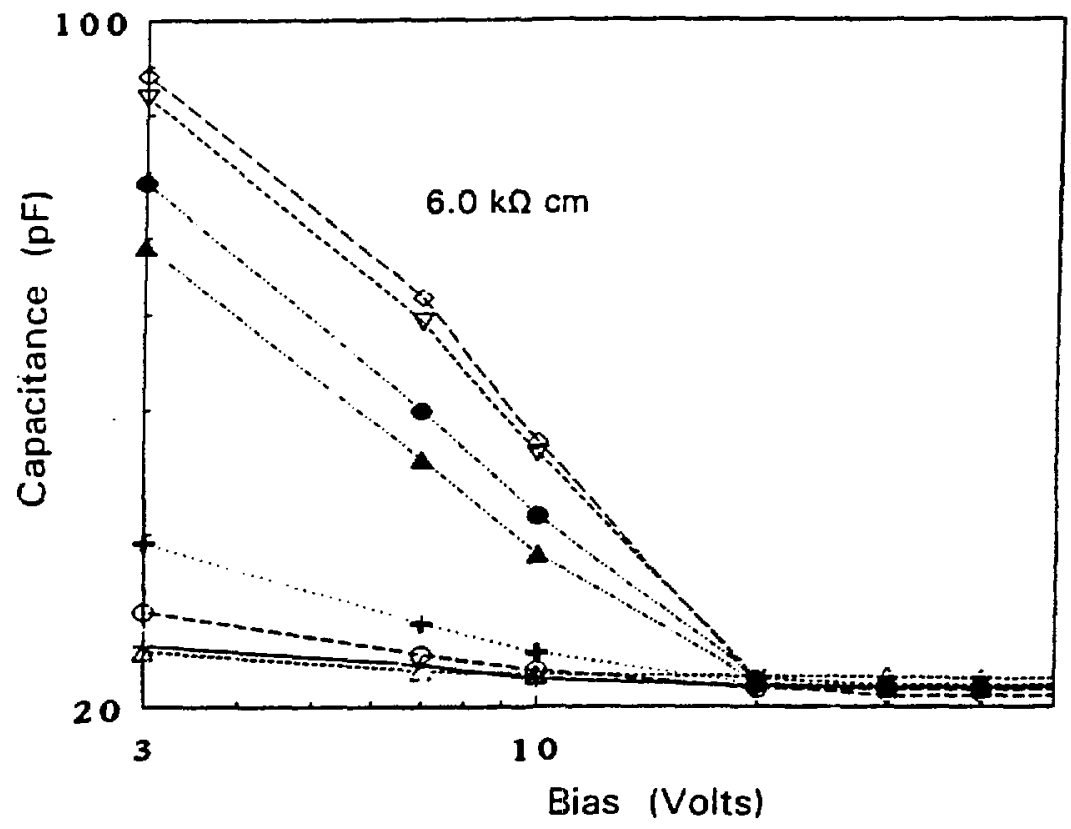

$\longrightarrow \quad 1$ MHz

$-\Delta-500 \mathrm{KHz}$

$--\Theta-100 \mathrm{KH} \mathbf{H z}$

$+\cdots \quad 50$ KHz

$-10 \mathrm{KHz}$

s $\mathrm{KHz}$

$\cdots 1$ KHz

$-\infty-0.5 \mathrm{KHz}$

b) Neutron irradiated to the fluence of $7.8 \times 10^{12} / \mathrm{cm}^{2}$ 
MOS CAPACITOR before n-rad.

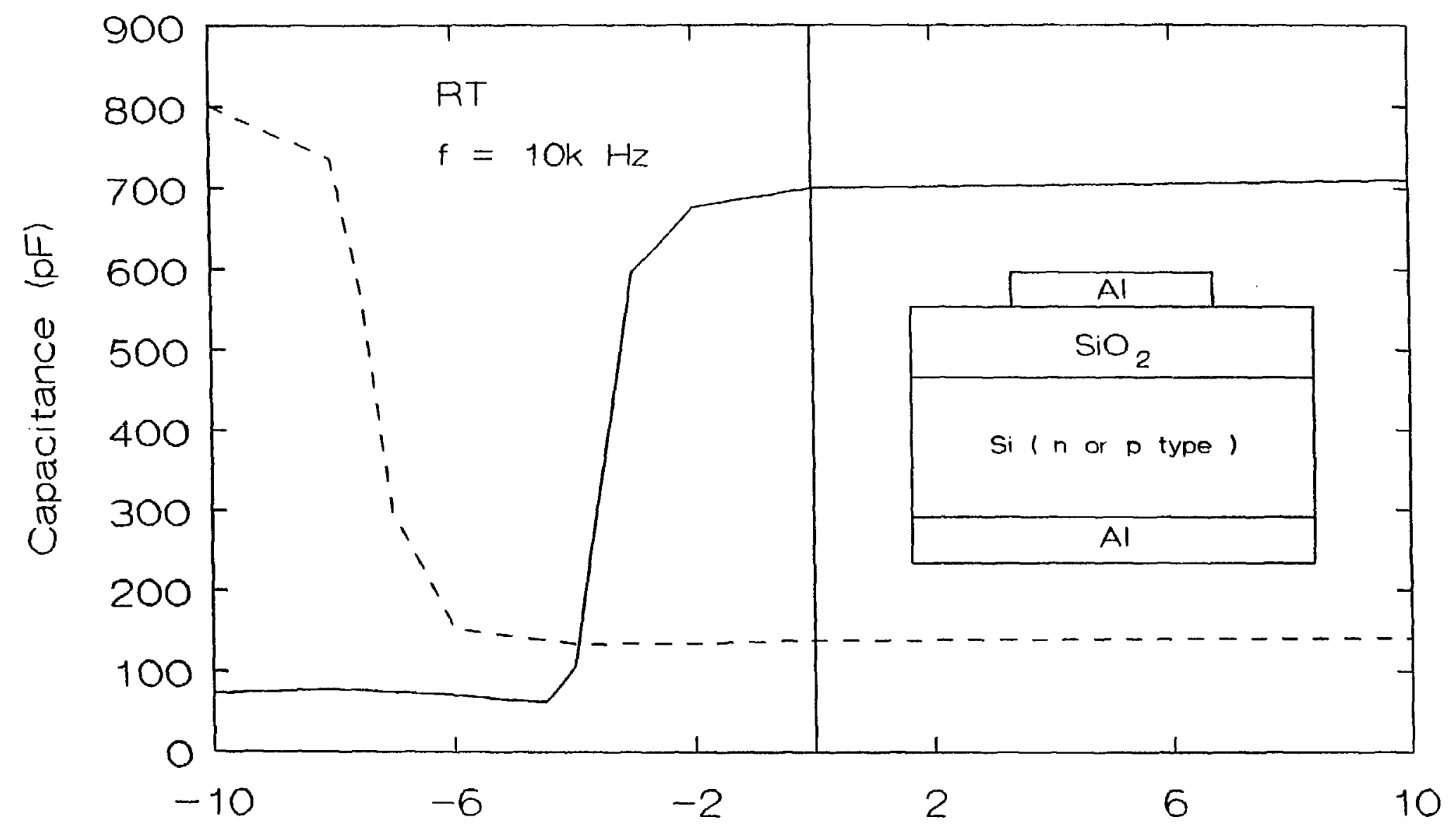

Gate Bias (Volts)

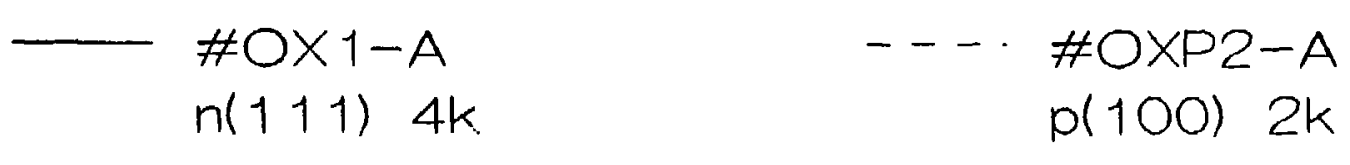


MOS CAPACITOR UNDER $n$-RADIATION

$n-T Y P E ~ S i, ~ \# N 5-C, f=10 \mathrm{KHz}, 2 \mathrm{Kohm}-\mathrm{cm}$

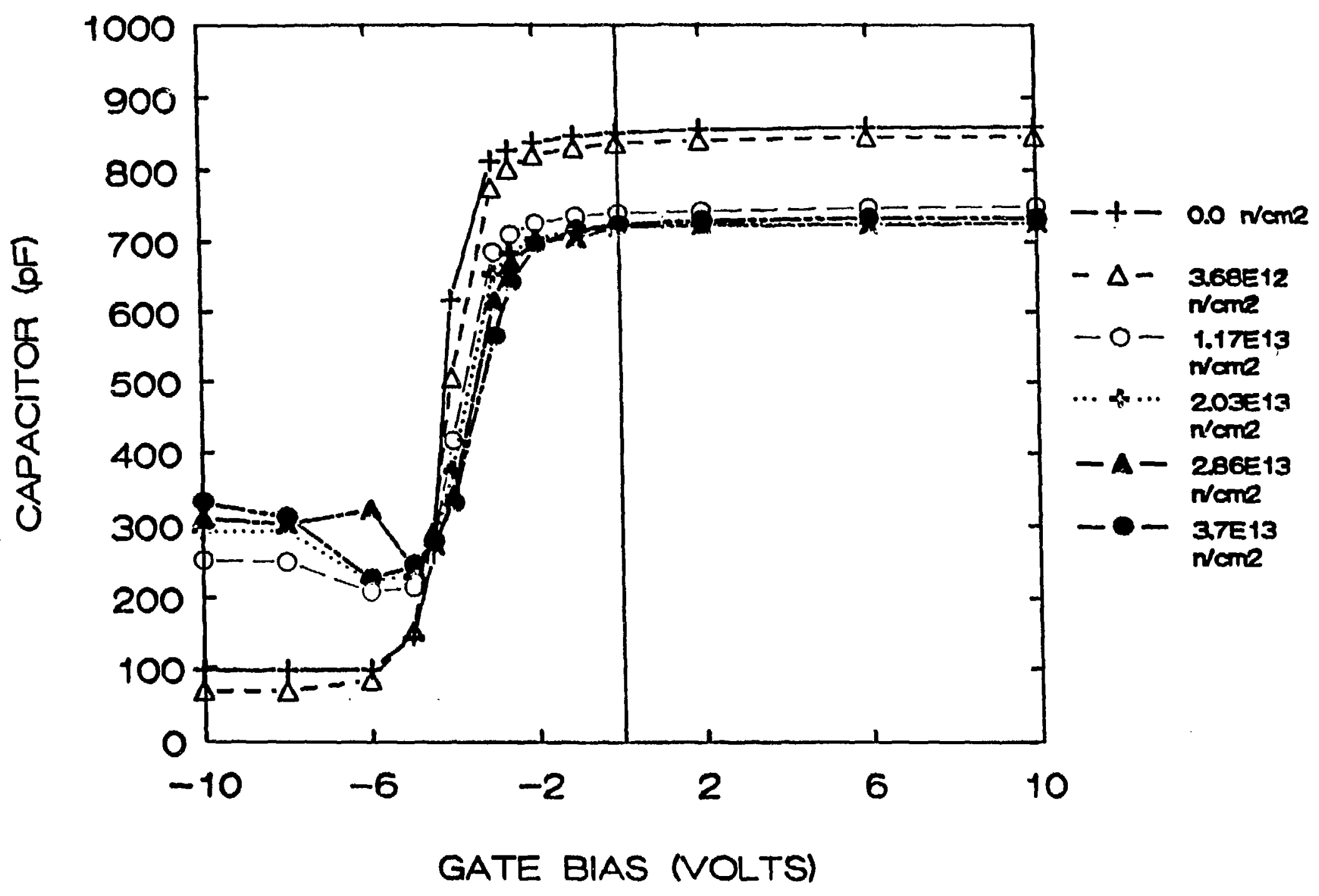


MOS CAPACITOR UNDER N-RADIATION

$n$-TYPE Si, \#N6-C, $f=10 \mathrm{KHz}, 4-5 \mathrm{Kohm}-\mathrm{cm}$

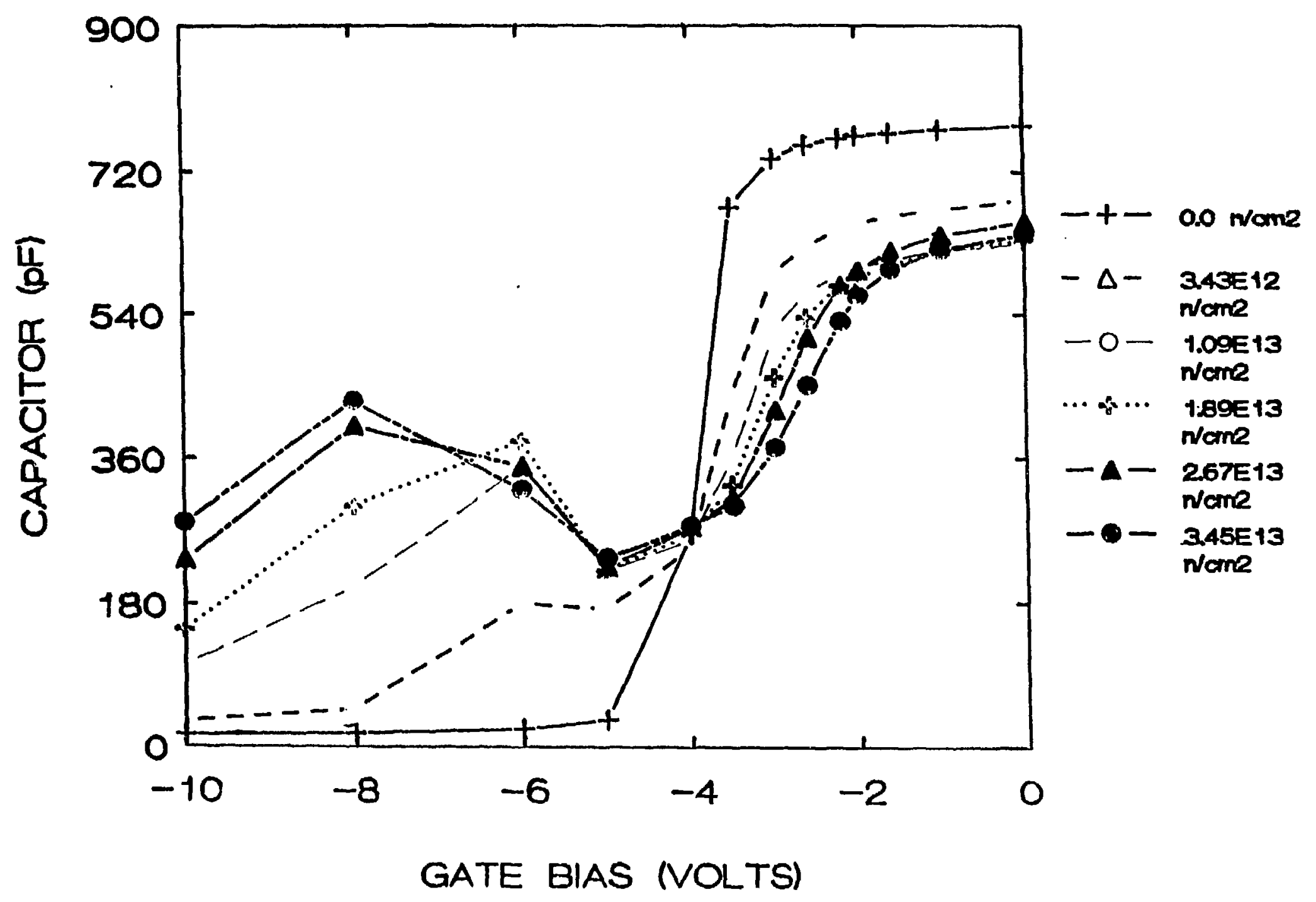


MOS CAPACITOR UNDER n-RADIATIQN 0.0 nome n-type $\mathrm{Si}, \# N 3-B, f=10 \mathrm{KHz}$

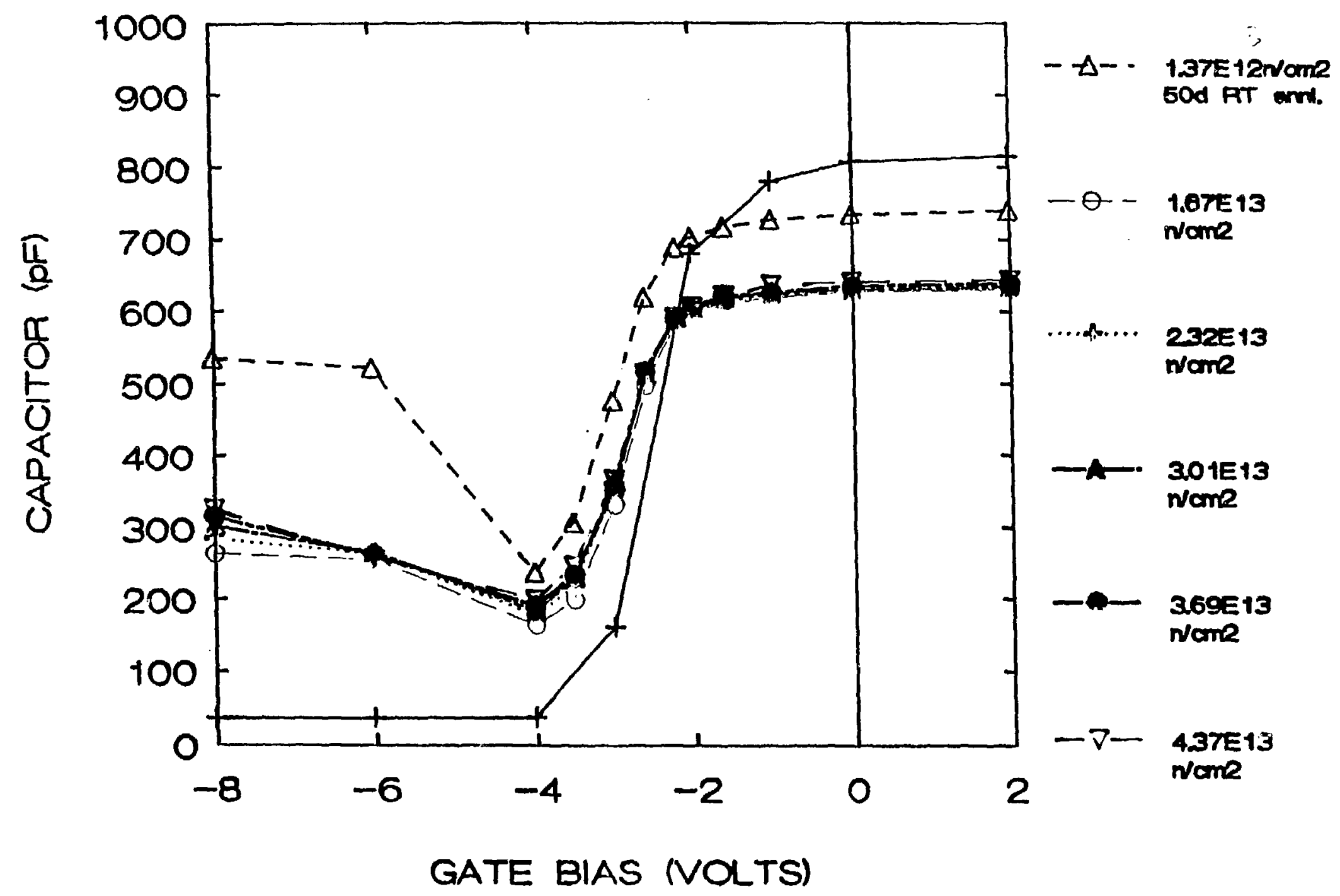


ni111) 1OK ohm-cm, no n-damage

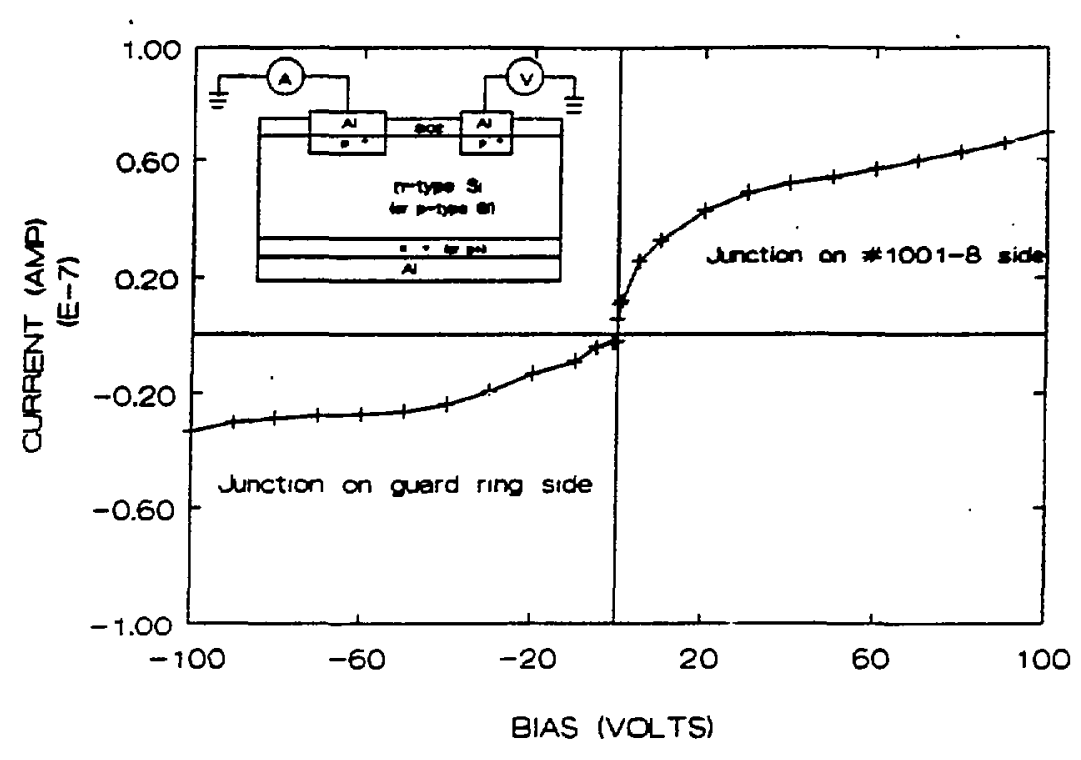

a) $p+/ n / p+/$ back to back diode

\#60-2. p(111) 5kohm-cm. no n-damage

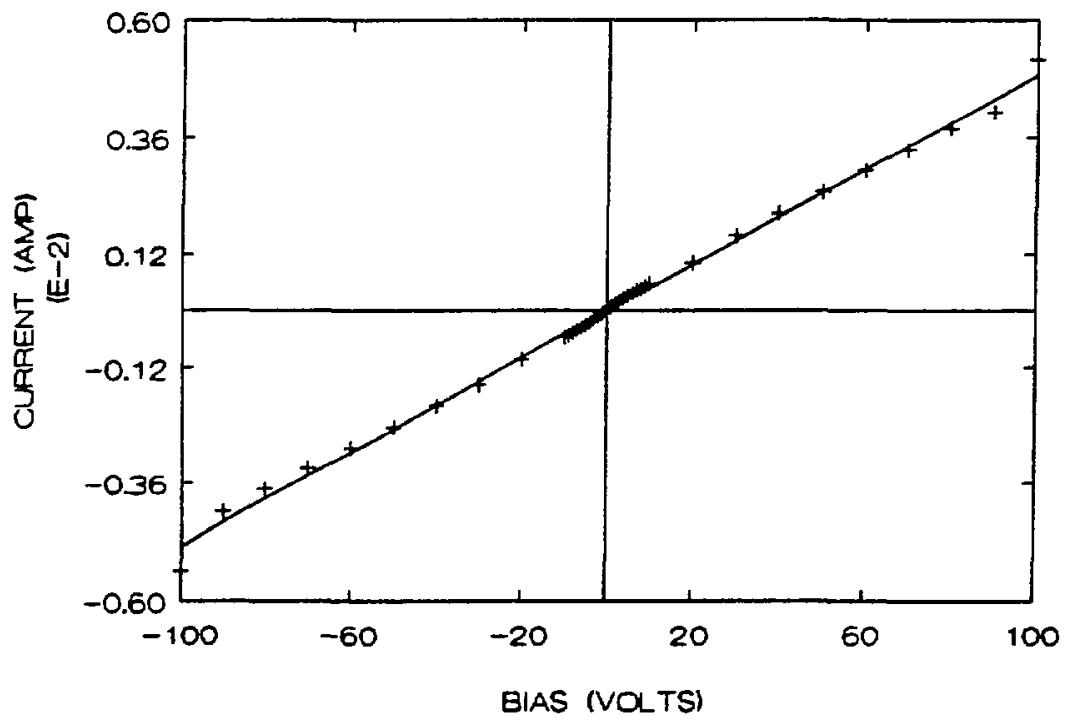

b) $p+/ p / p+$ resistor 


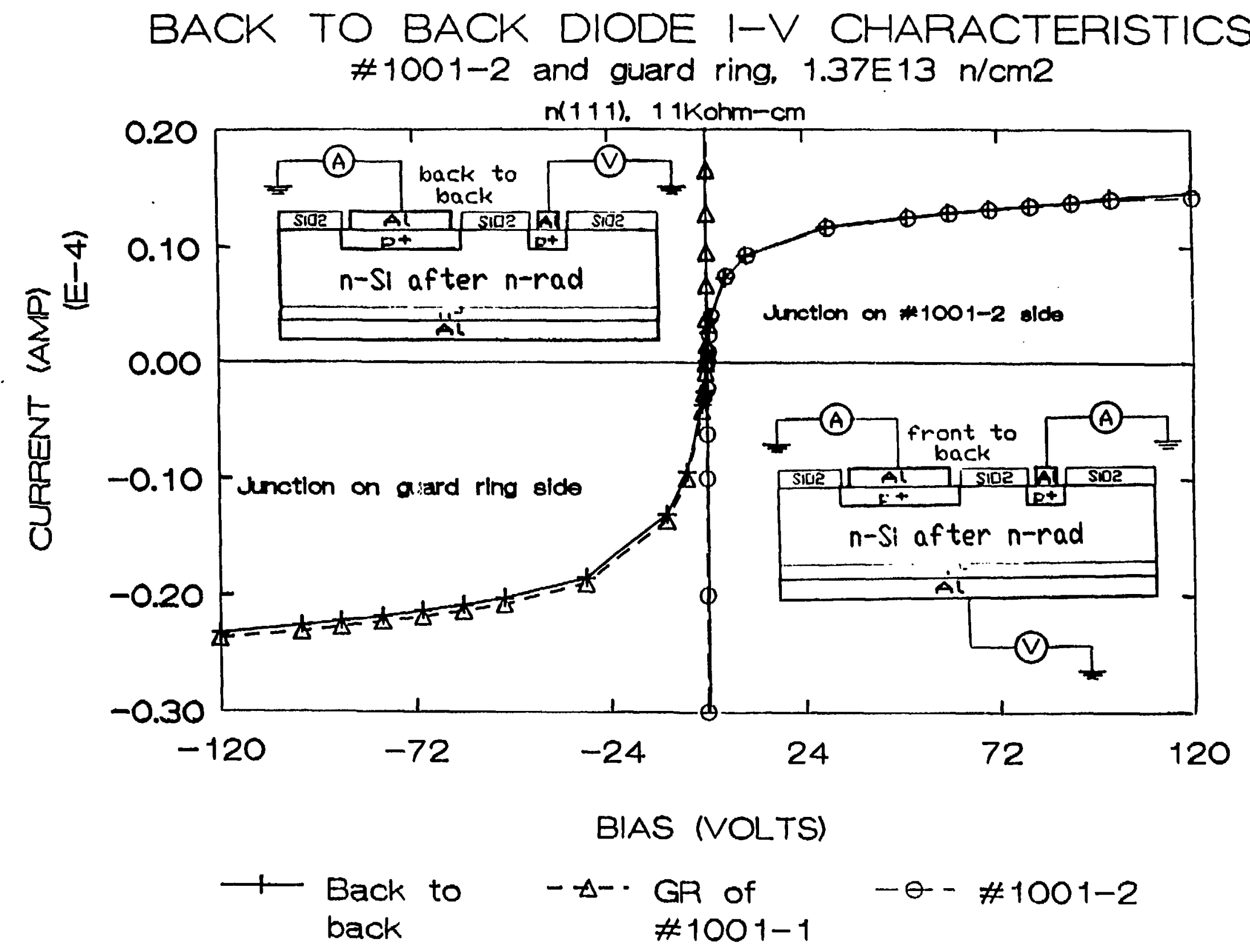




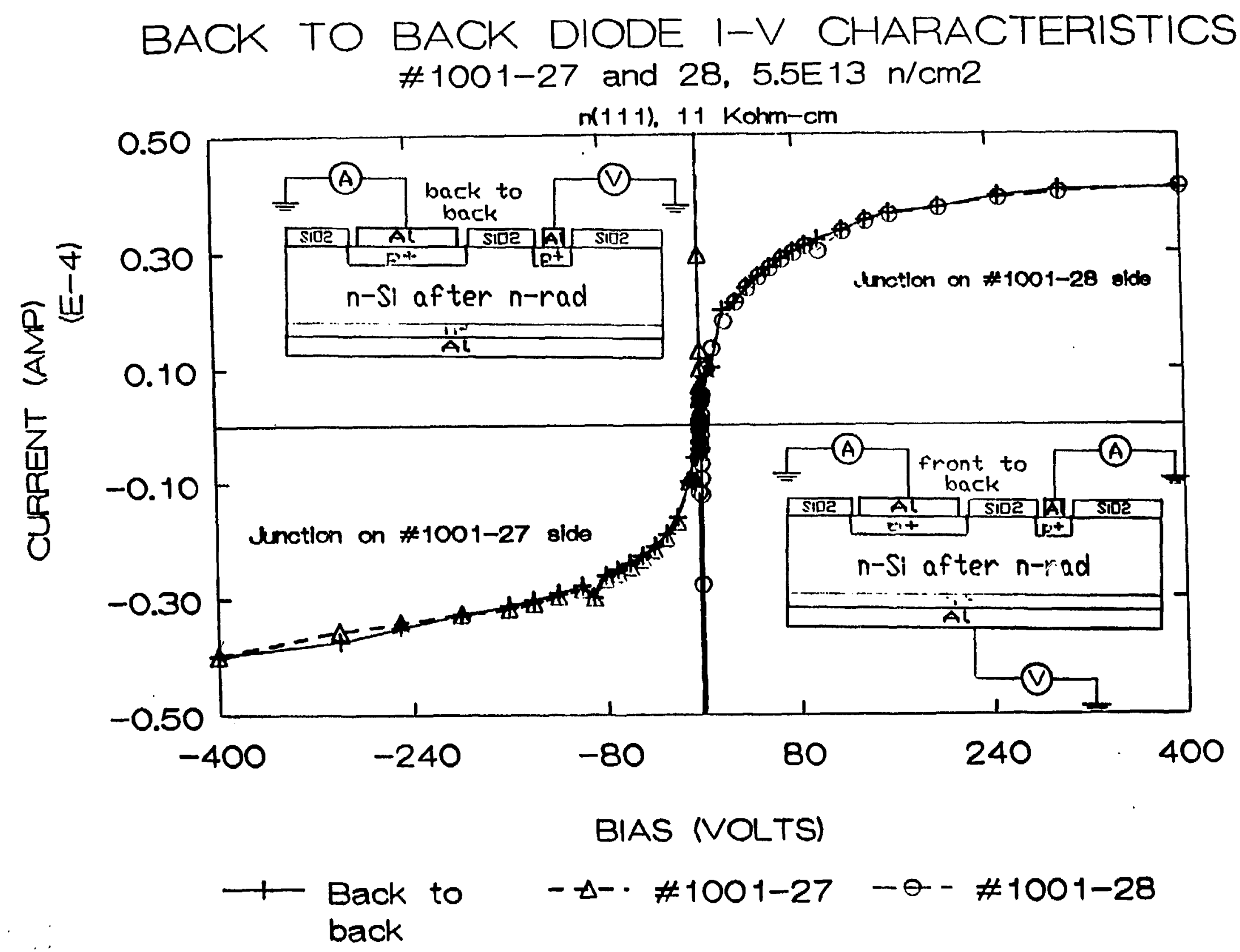




\section{DETECTOR 133-1 \\ CONTROL NO NEUTRONS}

alphas on front

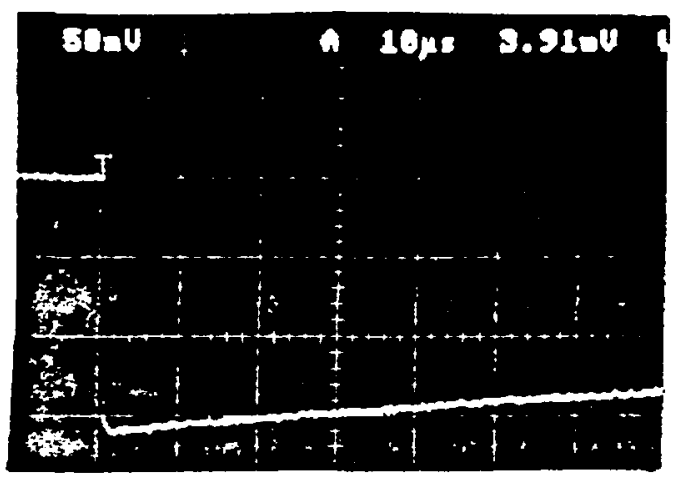

alphas on back

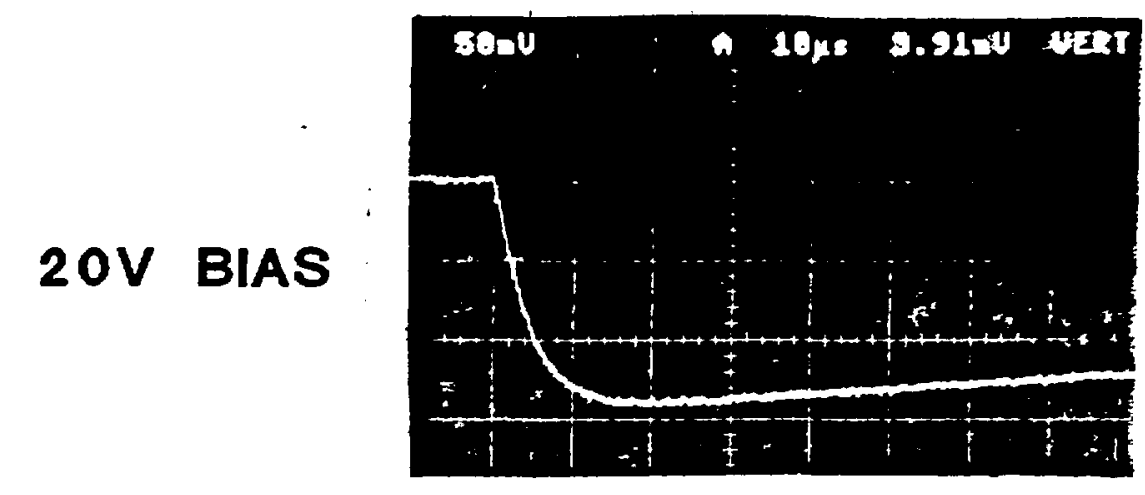

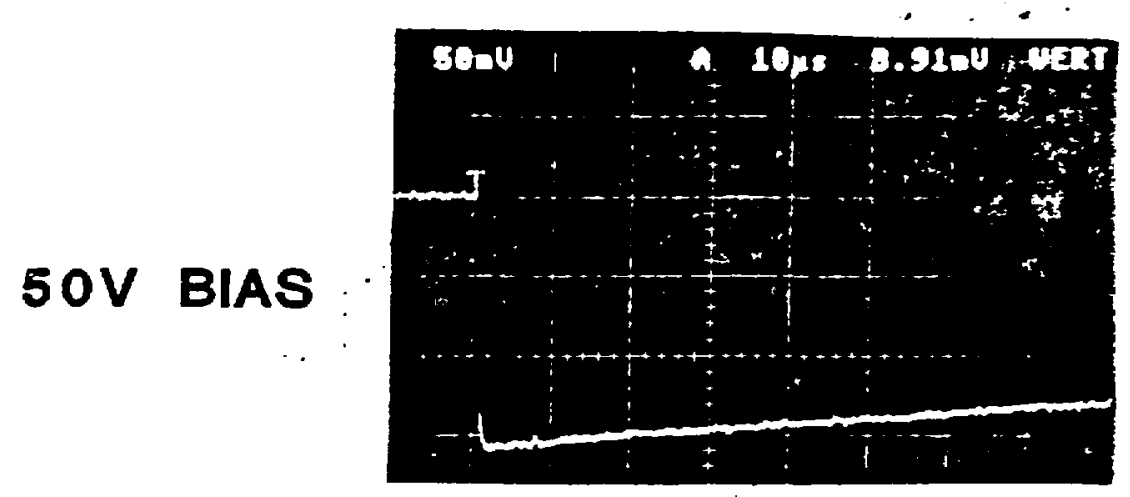




\section{alphas on front}
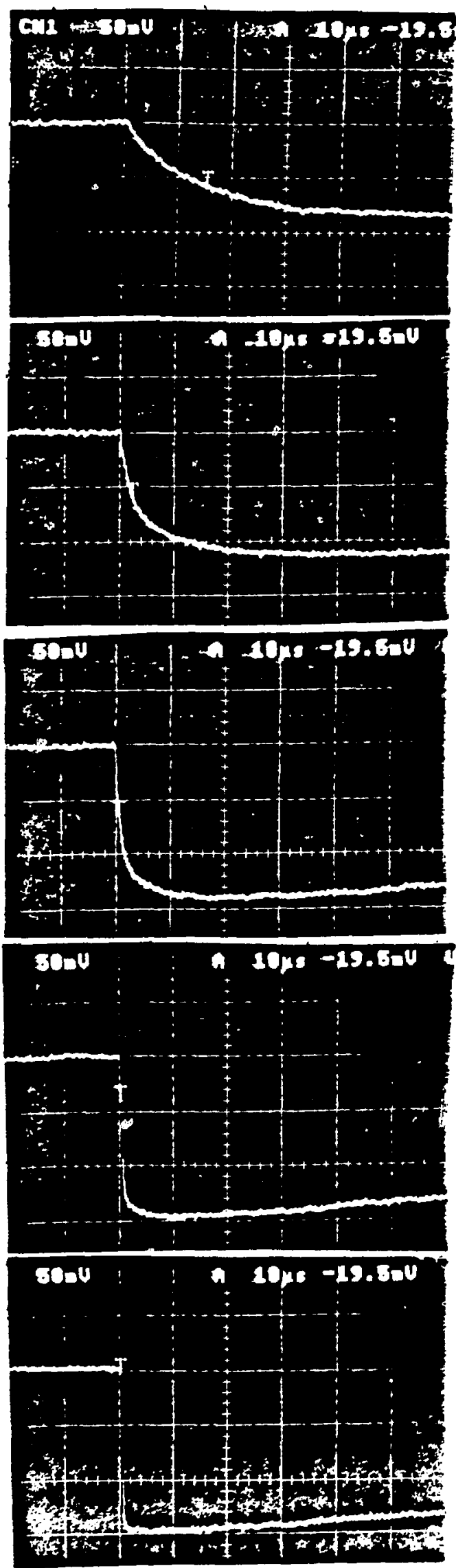

DETECTOR 130-10 C OXIDE $6 \mathrm{E} 12 \mathrm{n} / \mathrm{cm} 2$

$20 \mathrm{~V}$

\section{$50 \mathrm{~V}$}

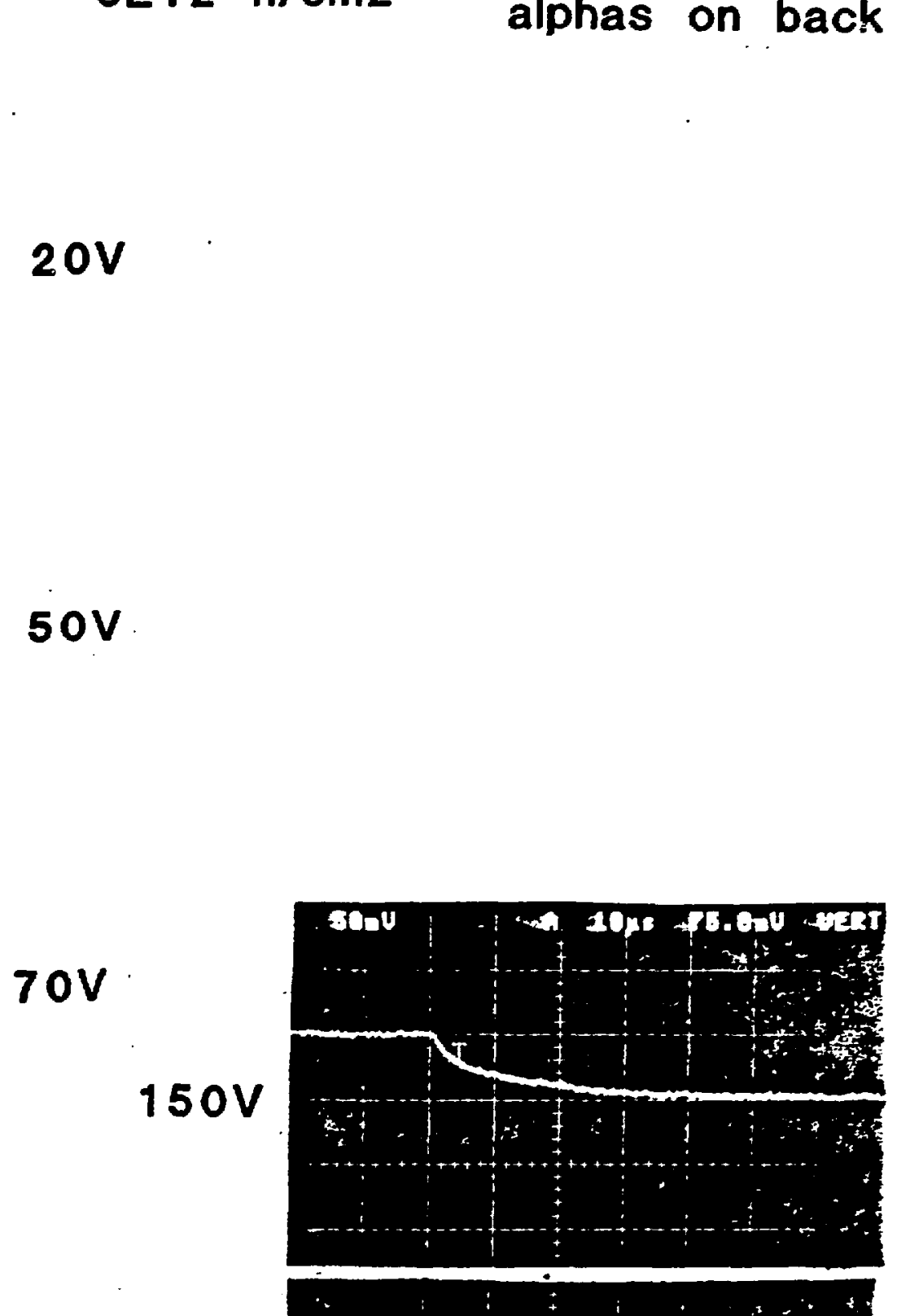

$100 \mathrm{~V}$ 


\section{alphas on front}
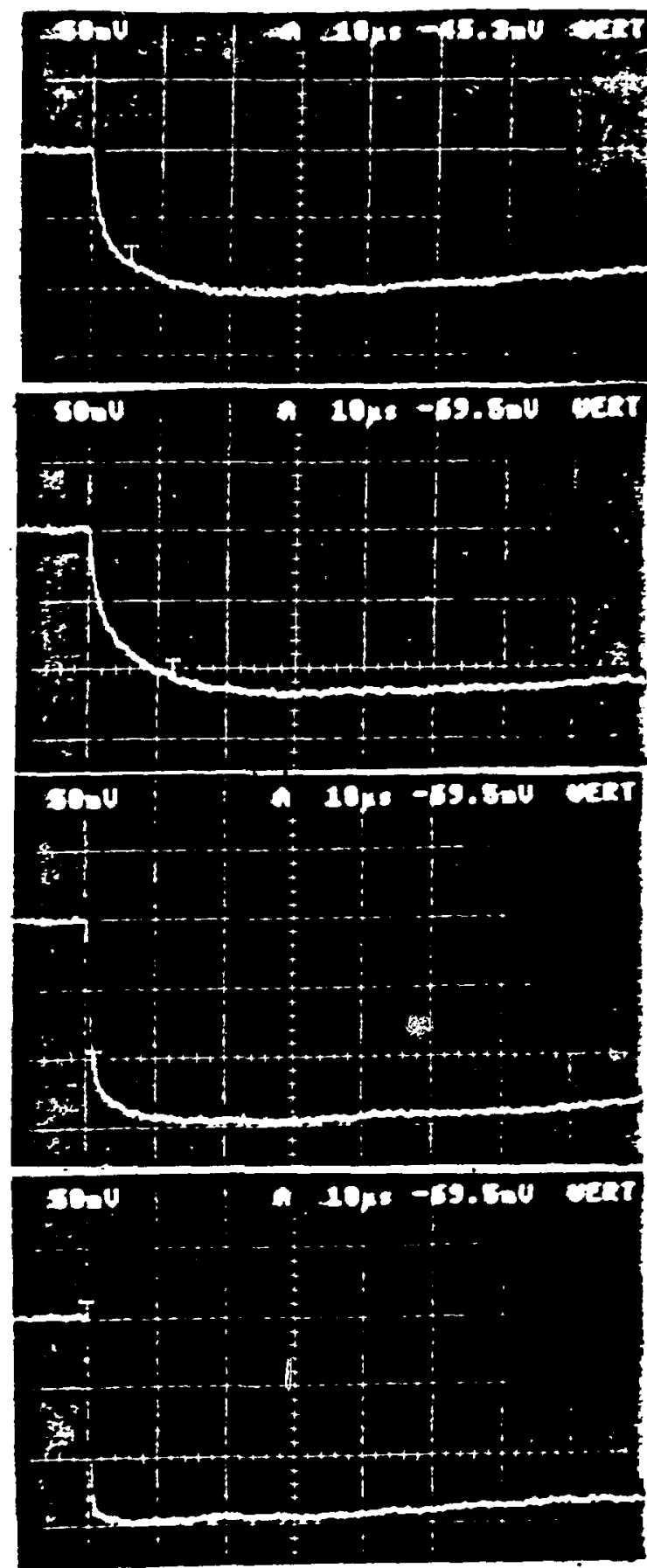

301

- 1028-59.80u cant

II

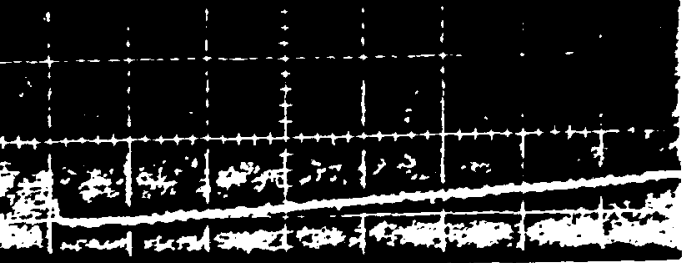

DETECTOR $133-9$

\section{$6 \mathrm{E} 12 \mathrm{n} / \mathrm{cm} 2$}

\section{alphas on back}

\section{$20 \mathrm{~V}$}

$50 \mathrm{~V}$

$100 \mathrm{~V}$

$150 \mathrm{~V}$

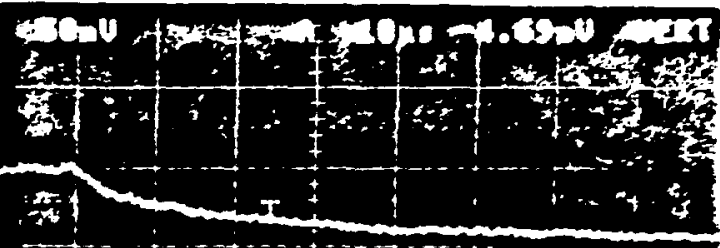

$150 \mathrm{~V}$

$200 \mathrm{~V}$

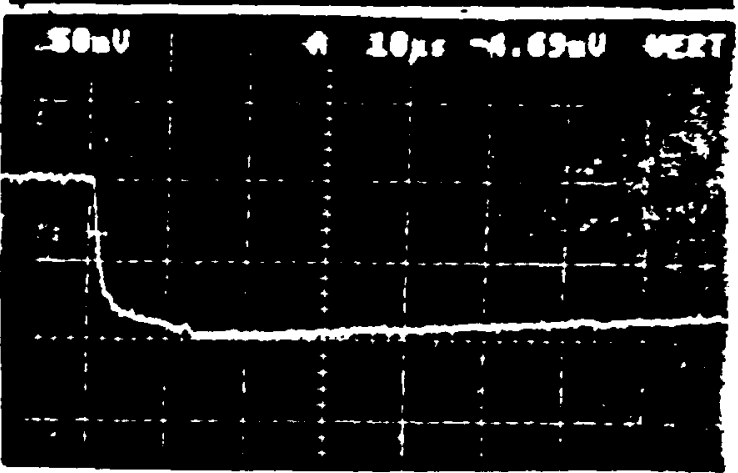

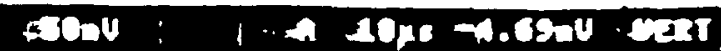

$250 \mathrm{~V}$

$200 \mathrm{~V}$ 3ev

a 1018 -21.104 nas

th.

in

$300 \mathrm{~V}$ 


\section{DETECTOR 107-1 \\ $5 E 11 \mathrm{n} / \mathrm{cm} 2$}

\section{alphas on front}

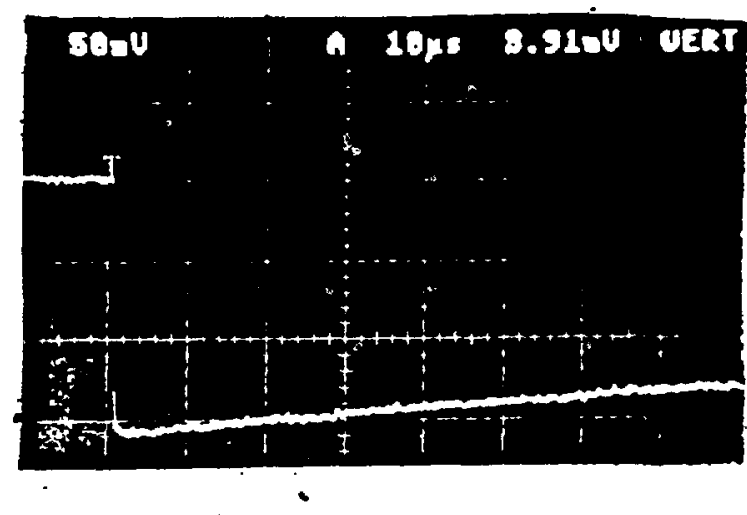

alphas on back
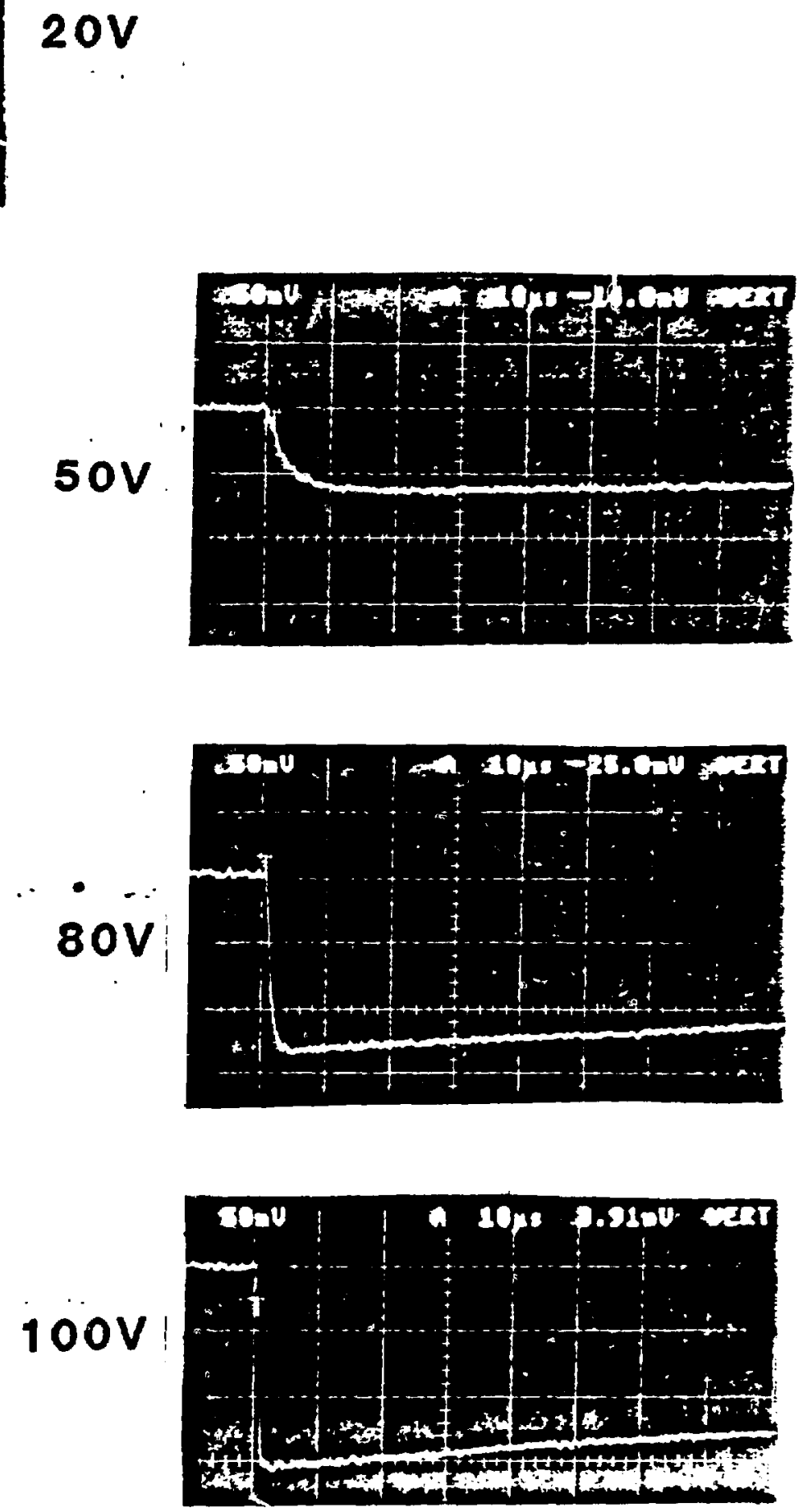


\section{DETECTOR 133-2}

\section{$1.6 \mathrm{E13} \mathrm{n} / \mathrm{cm} 2$}

alphas on front

alphas visible at $100 \mathrm{~V}$
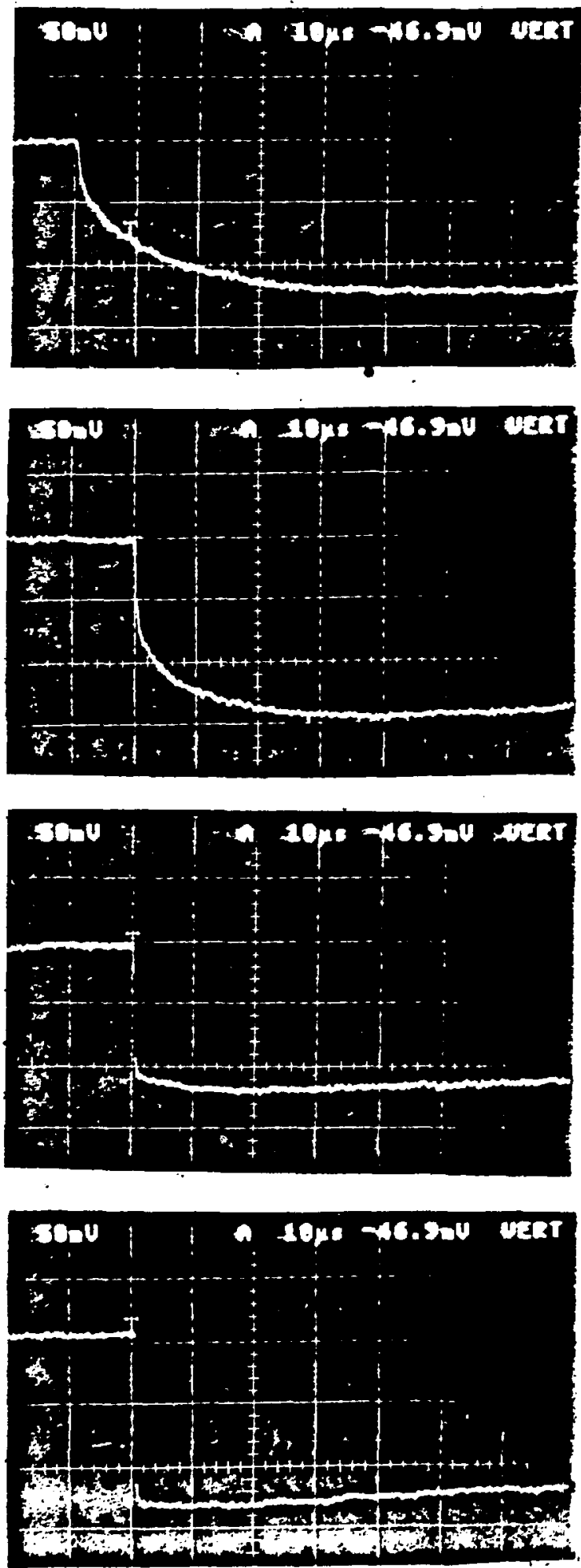

$450 \mathrm{~V}$

$300 \mathrm{~V}$

\section{$400 \mathrm{~V}$}

alphas on back

no alphas visible at $100 \mathrm{~V}$
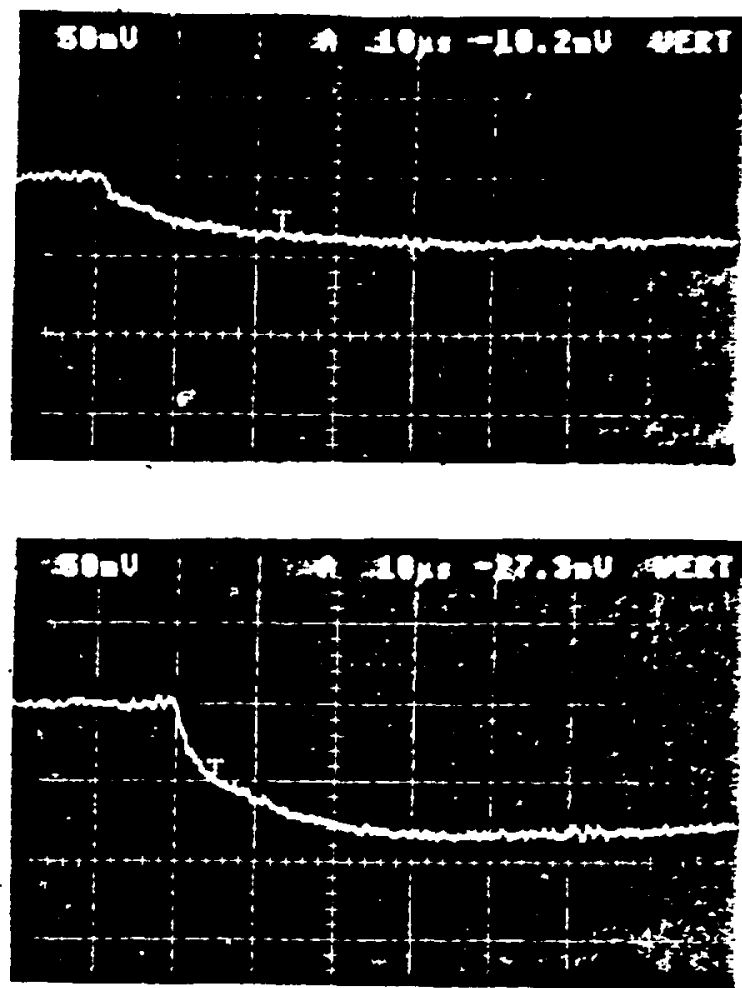

snat

vent
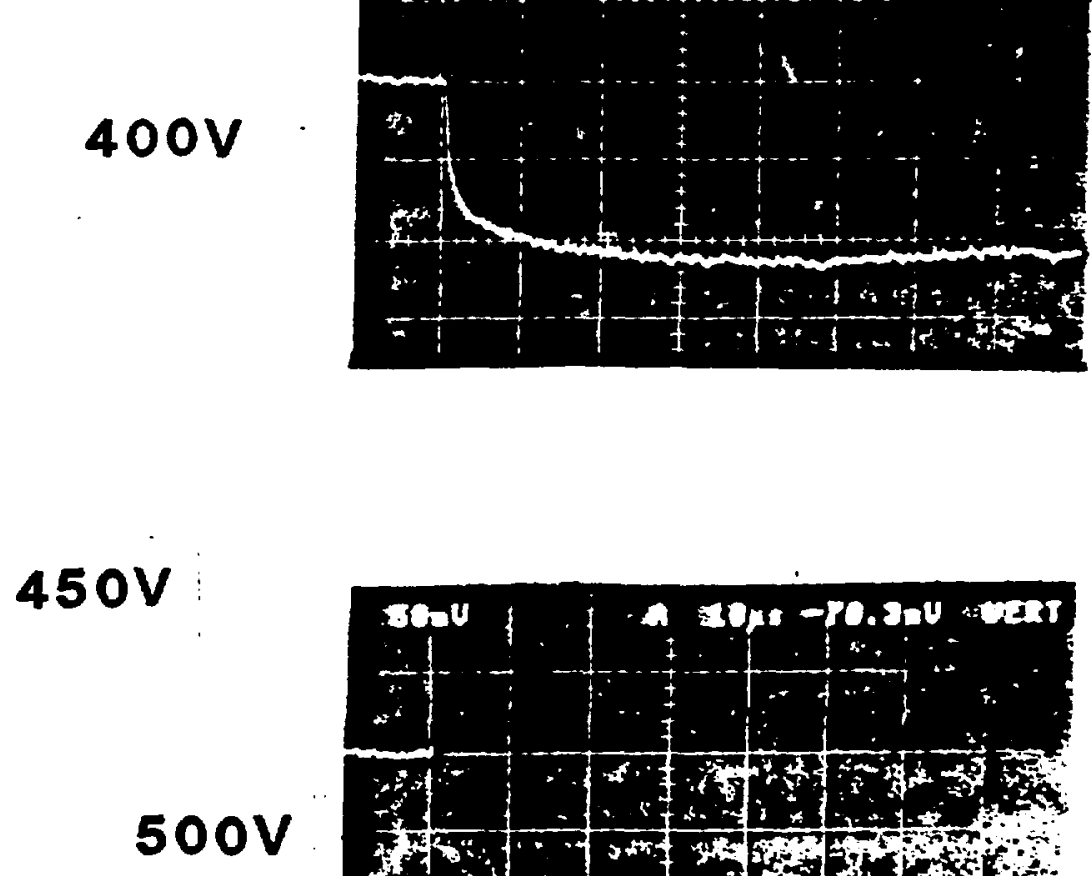


\section{DETECTOR 1001-27 \\ $5 E 13 \mathrm{n} / \mathrm{cm} 2$}

alphas on front

$200 \mathrm{~V}$
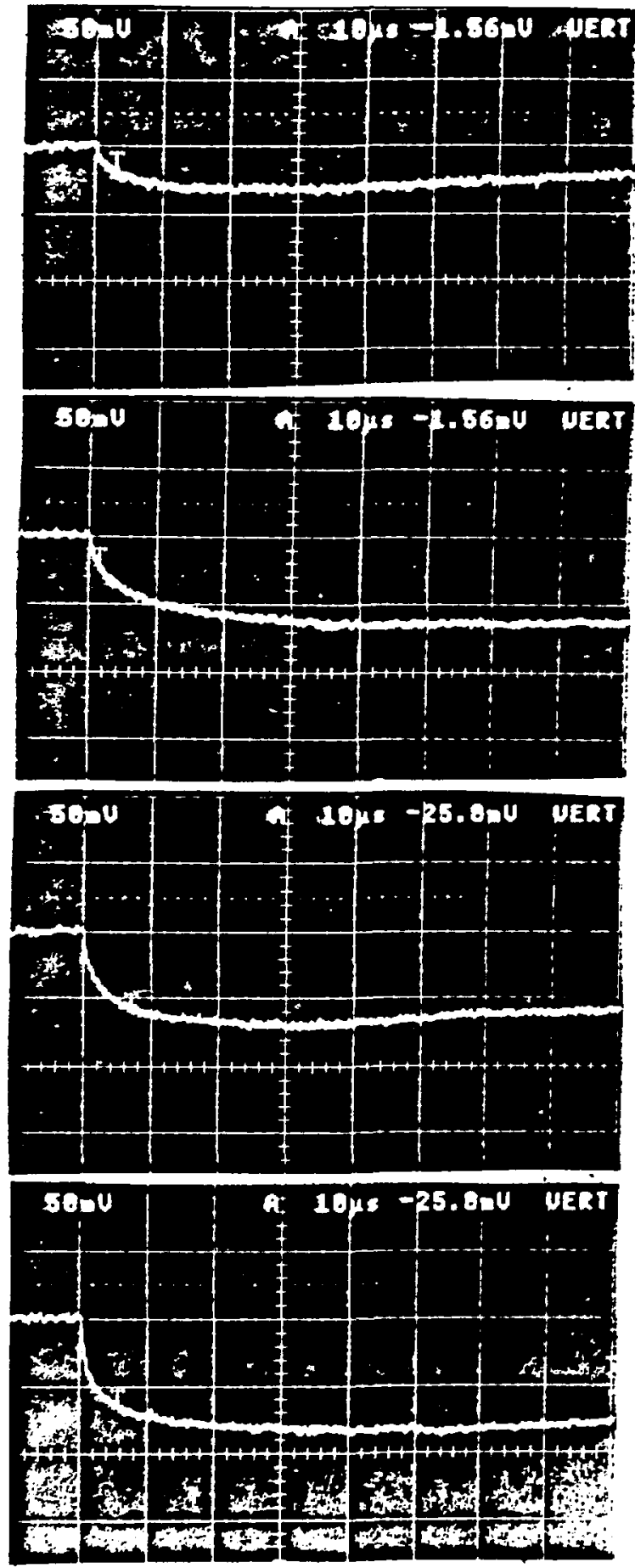

$300 \mathrm{~V}$

$400 \mathrm{~V}$

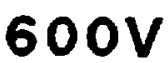

\section{alphas on back}
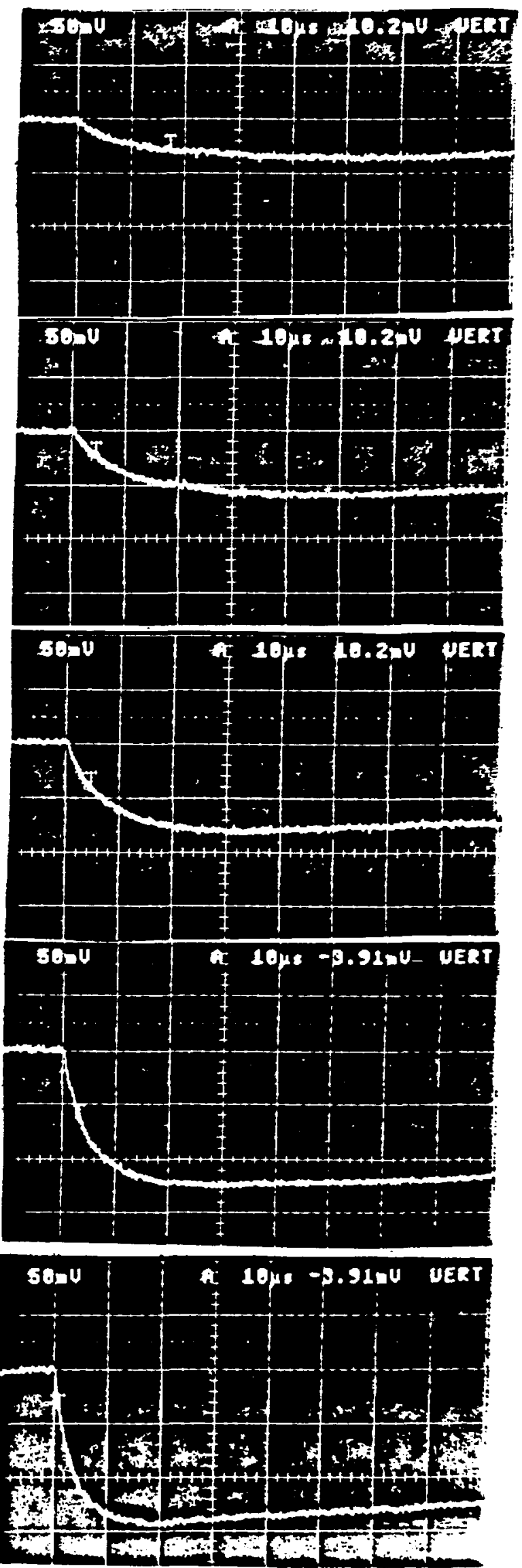
FULL DEPLETION VOLTAGE VS. n-FLUENCE \#1001-28, n(111), 11 Kohm-cm

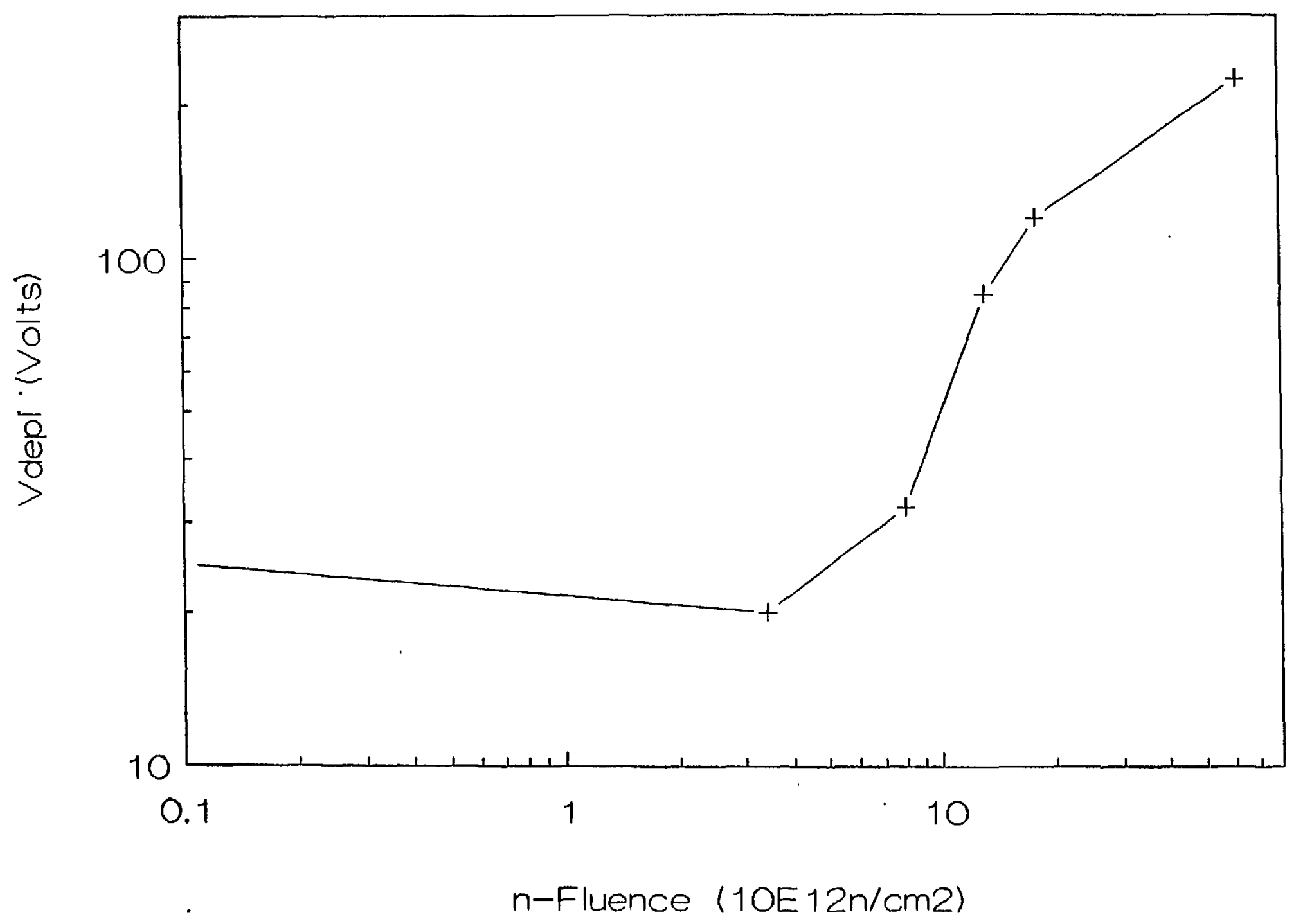




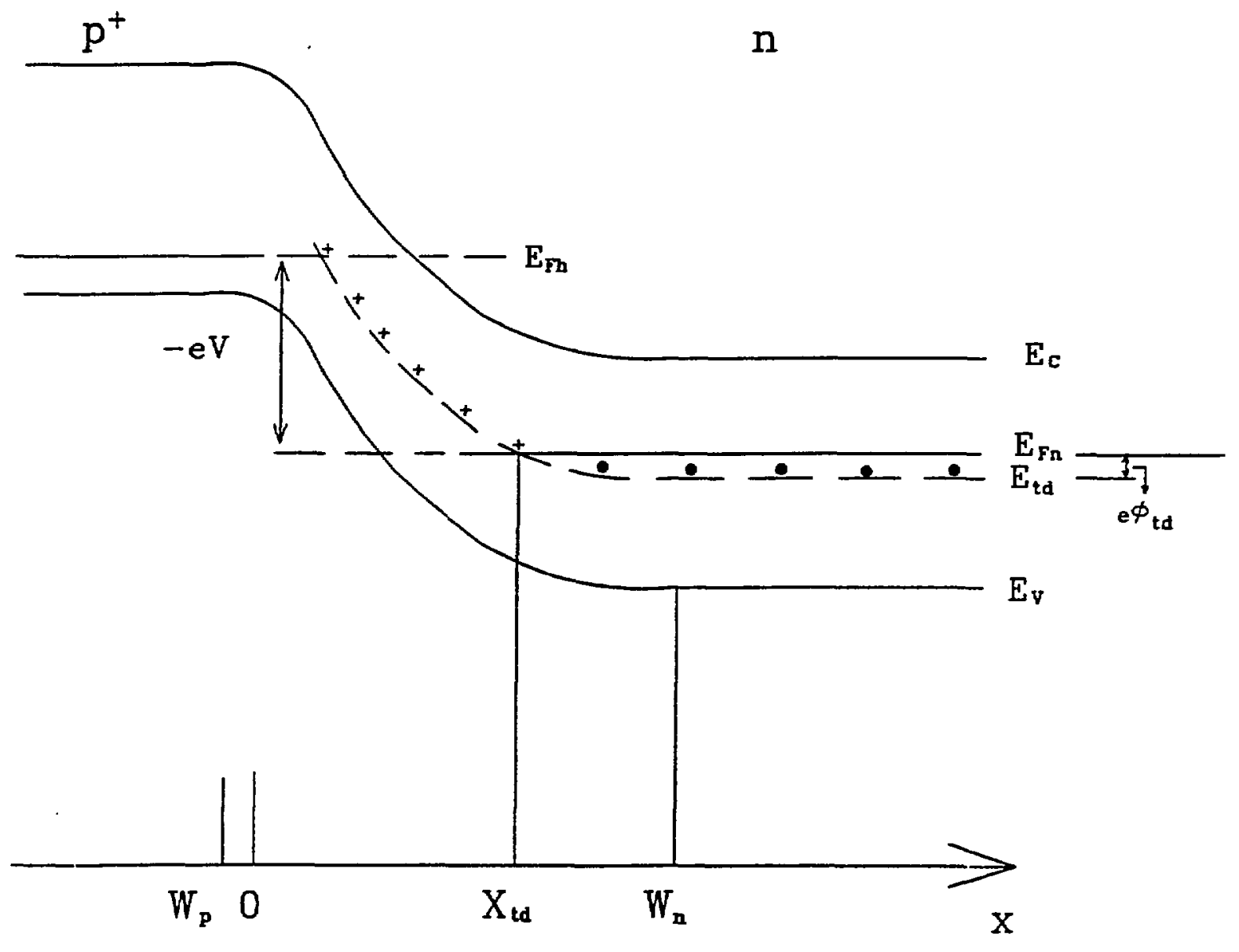




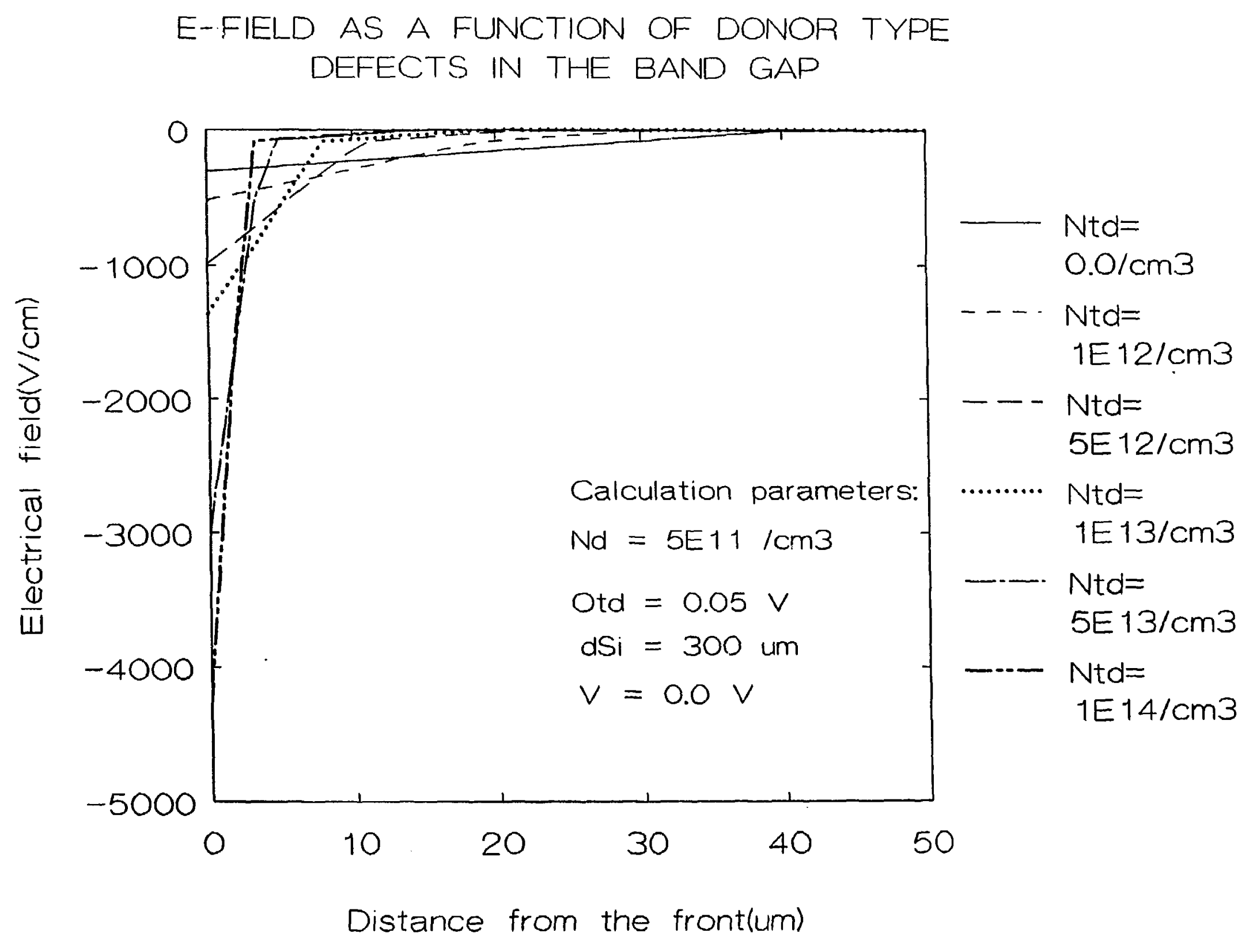




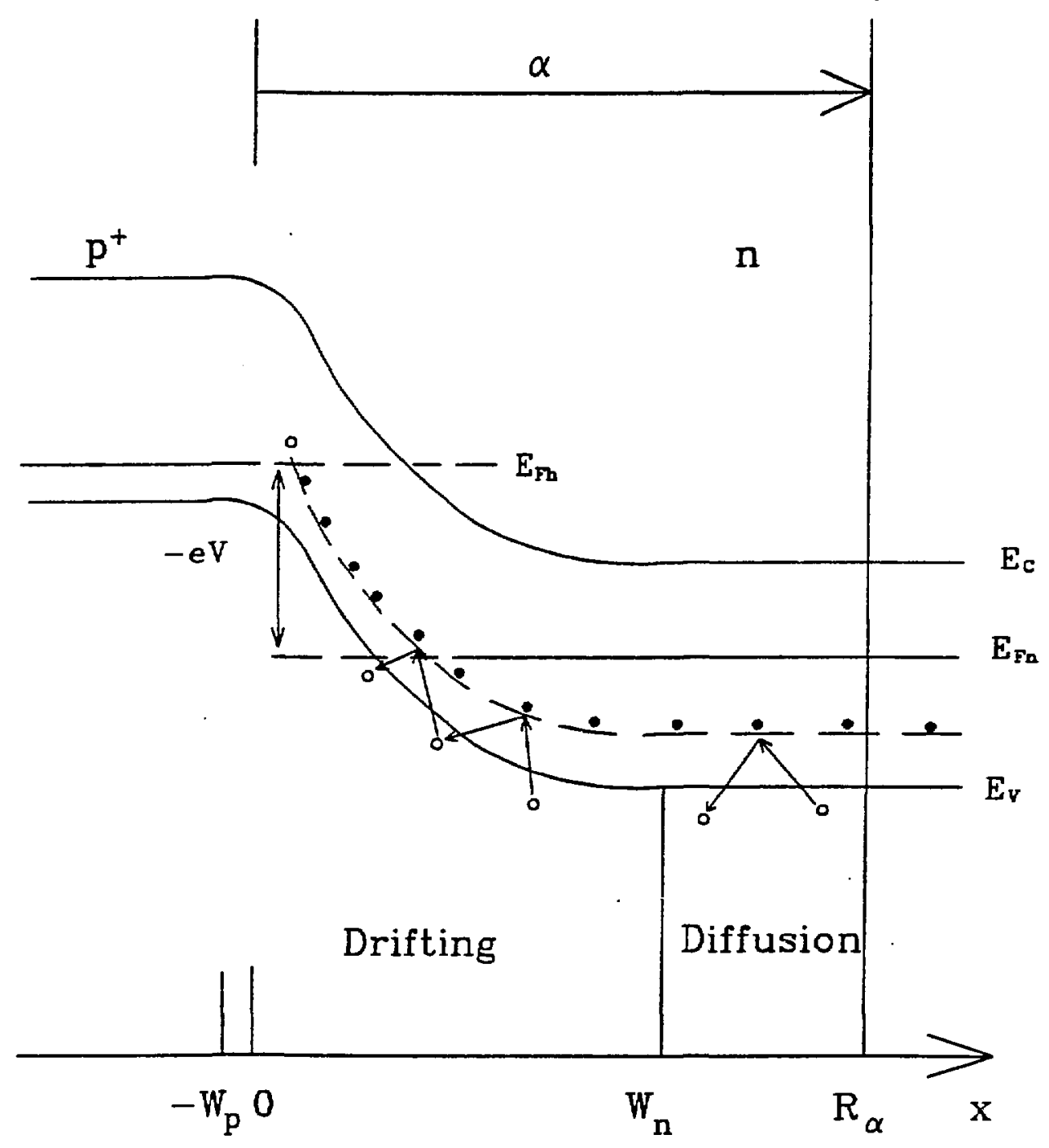


FULL DEPLETION VOLTAGE AS A FUNCTION OF CONCENTRATION OF DONOR-LIKE TRAPS (Ntd)

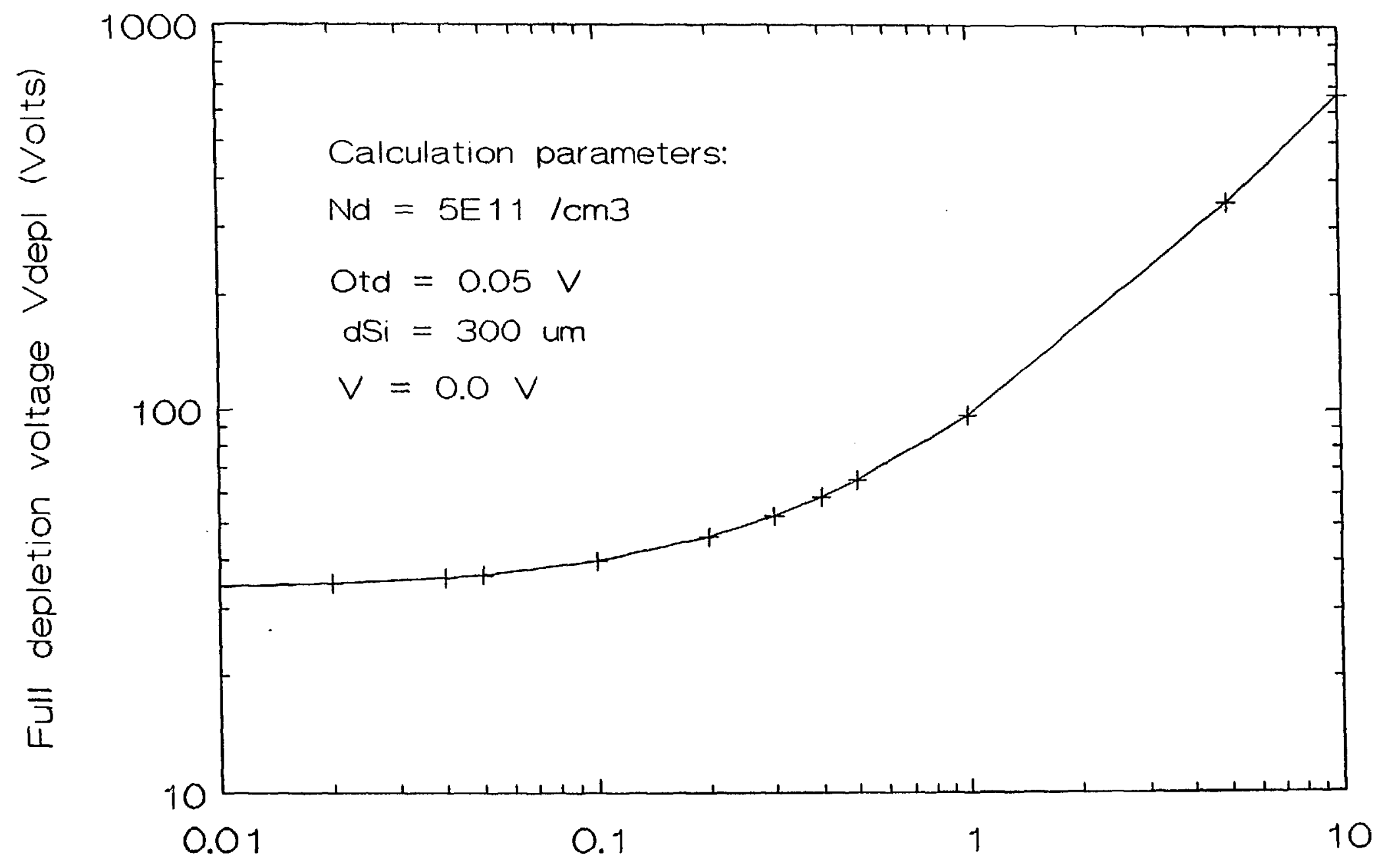

Concentration Ntd $(1 \mathrm{OE} 12 / \mathrm{cm} 3)$ 